\title{
Current Situation and Issues Regarding the Accessibility of Beijing Daxing International Airport - Beijing Daxing International Airport Opened in September 2019
}

\author{
MIZUNO Tomomi $^{1} \&$ TOKUDA Katsumi ${ }^{1}$ \\ ${ }^{1}$ Faculty of Medicine, University of Tsukuba, Japan. \\ ORCID: 0000-0002-7213-0483 (Tokuda)
}

\begin{abstract}
Located $50 \mathrm{~km}$ south of the heart of Beijing, Beijing Daxing International Airport opened in September 2019. The objective of this paper is to discuss barriers in the accessibility of the elderly and people with disabilities at the airport based on the result of field investigation.

The field investigation was conducted to find barriers in the following areas: a) Braille blocks in the airport, b) Slopes in the airport, c) Wheelchair-accessible restrooms in the airport, d) Elevators in the airport, e) Information centers in the airport, f) Sign boards in the airport, g) Ticket booth of a subway station, h) Accessibility to a subway station platform, i) Subway station platform, j) Wheelchair-accessible restrooms of a subway station, k) Interior of a subway car, 1) Ticket booth of a highspeed train station, m) Accessibility to a high-speed train station platform, n) High-speed train station platform, o) Wheelchair-accessible restrooms of a high-speed train station, p) Interior of a high-speed train car, q) Accessibility to a taxi stand, r) Transportation within an airport parking lot, s) Wheelchair-accessible parking space, t) Wheelchair-accessible restrooms of an airport parking lot,
\end{abstract}

The field investigation was conducted for three days between December 20 and 22, 2019.

From the viewpoint of accessibility, there were facilities which could not be used by wheelchair users independently, unlike the wheelchair-accessible restroom in a subway station. There was also an inconsistency in design, namely the arrangement of a standing urinal with a handrail. The airport had many other barriers to be overcome and it is highly expected that these issues will be cleared in near future based on the opinions of airport users.

Keywords: accessibility, barrier free, Beijing Daxing International Airport

\section{INTRODUCTION}

Beijing Daxing International Airport, located $50 \mathrm{~km}$ away from the central part of Beijing city, was opened in September 2019. The airport is graded by the Chinese government as a hub of the crucial transportation system for the development of the nation as well as a drive to provide a boost to "Belt and Road" initiative.
The starfish-shaped terminal building, designed by architect Zaha Hadid, has the largest square footage in the world $\left(1,030,000 \mathrm{~m}^{2}\right)$, currently equipped with four runways. The terminal is scheduled to have eight runways at final completion expecting a capacity for more than 120 million passengers. Moreover, state-of the-art technologies, including 5G, AI, and robots, will transform the airport into a "smart airport".

The terminal rises five stories above the ground and two underground stories. There are restaurants on the fifth floor while the third and the second floor serves as domestic departure and domestic arrival gates respectively. The fourth floor serves as departure gate for international flights. The international arrival gates are located on the ground floor along with taxi and shuttle bus stands. The airport terminal has a direct access to subway, Beijing Daxing International Airport Express, as well as high-speed railway, Beijing-Xiong'an Intercity Railway, via the first basement level. The platforms for the high-speed railway and the subway are located on the second basement level. The user-friendly traffic accessibility is the signature of Beijing Daxing International Airport. It is only 19 minutes from Caoqiao Station of Line 10 and the minimum approx. 30 minutes from Beijing West railway station.

It is unprecedented to construct an airport having all the smartness of scientific technologies concentrated and taking users convenience into consideration. It can be easily imagined that diversity of users has been considered in design and construction of the airport.

We have conducted various surveys, including a survey for barrier-free situation of the Chinese railways [1] , an environment assessment for indoor play facilities in China [2] , as well as Tactile walking surface indicators survey in Tibet Autonomous Region and Xinjian Uygur Autonomous Region

[3]. We also conducted a survey for bicycle sharing that has become a new obstacle in urban areas in China due to abandoned bicycles on the street [4]. By doing that, we have pointed out specific challenges and solutions for the barrier-free issues in China.

In this article, we will shed light on potential barriers in Beijing Daxing International Airport that may be realized by the disabled and the elderly and discuss, based on the findings from the field research, how the problems should be solved. 
International Journal of Engineering Research and Technology. ISSN 0974-3154 Vol.13, No.4 (2020), pp. 768-782

(C) International Research Publication House. https://dx.doi.org/10.37624/IJERT/13.4.2020.768-782

\section{METHOD}

\section{Procedure and survey site}

The survey was conducted using "Barrier-discovery-type field work [5] ". In the Barrier-discovery-type field work, we first get a grasp of some characteristics of the walking and needs of the people who may need assistance while moving around, including the visually impaired, the people on wheelchair, the elderly, the people using stroller, as well as parents/guardians with small children, and then thoroughly check the area by actually moving around to find out what sort of barriers are there to inhibit them from using the facility safely and comfortably [5-9].

The focuses of the survey were (1) accessibility to the airport, railway station, bus/taxi stands, parking premises and facilities (whether they are able to use them safely, conveniently and comfortably), and (2) comfortableness at the places mentioned above (whether they are able to use the facilities comfortably in the same way as other users).

More specifically, we conducted the field work by looking for potential barriers in the following locations.

a) Tactile walking surface indicators in the airport

b) Slopes in the airport

c) Multipurpose bathrooms in the airport

d) Elevators in the airport

e) Information booth in the airport

f) Signposting in the airport

g) Ticket sales office in the subway station

h) Access to platform in the subway station

i) Platform in the subway station

j) Multipurpose bathroom in the subway station

k) Interior of the subway vehicles

1) Ticket sales office in the high-speed railway station

m) Access to platform in the high-speed railway station

n) Platform in the high-speed railway station

o) Multipurpose bathroom in the high-speed railway station

p) Interior of the high-speed railway vehicles

q) Access to taxi stand

r) Transportation within the airport parking

s) Parking space for the disabled

t) Multipurpose bathroom in the airport parking

u) Miscellaneous

2 . Period of survey

$>$ The survey had been conducted for three days between December 20 and December 22 in 2019.

\section{RESULTS AND CONSIDERATION}

a) Tactile walking surface indicators in the airport

$>$ No guidance blocks were found within the restricted area for domestic flights (Photo 1). Alert blocks are installed only in selected areas such as in front of multipurpose bathrooms. This may be appreciated in terms of not interfering with the people on wheelchair, cane users, and the people carrying roller case, however, as a precondition, there should be guide-helpers accompanying the visually impaired.

There are metal warning blocks installed in front of doors to all multipurpose bathrooms within the restricted area which are being barriers for the people on wheelchair trying to get in the bathroom (Photo 2). In those bathrooms there are urinals with handrail (Photo 3 ) that is supposedly intended to be used by the visually impaired. As a reason for that presumption, there are no urinals with handrail in the men's room near the multipurpose bathroom (Photo 4). The urinals with handrail are often used by cane users and the visually impaired. It is a worldwide rare case to find urinals with handrail installed in multipurpose bathrooms intending to be used by cane users and the visually impaired.

Unlike bathrooms in any other places, it is important for the airport to publicize the fact that urinals with handrail are provided in multipurpose bathrooms because otherwise these urinals with handrail would not be used after all, and people would think "there are no urinals with handrail in the new airport".

$>$ Outside the restricted area, there are warning blocks installed in front of escalators (Photo 5), staircases (Photo 6) and elevators (Photo 7). There are also guidance blocks in front of elevators, but the purpose of that installation is not clear (Photo 8). Alert blocks are installed extending the full width of the elevator door, which is being a barrier for other users.

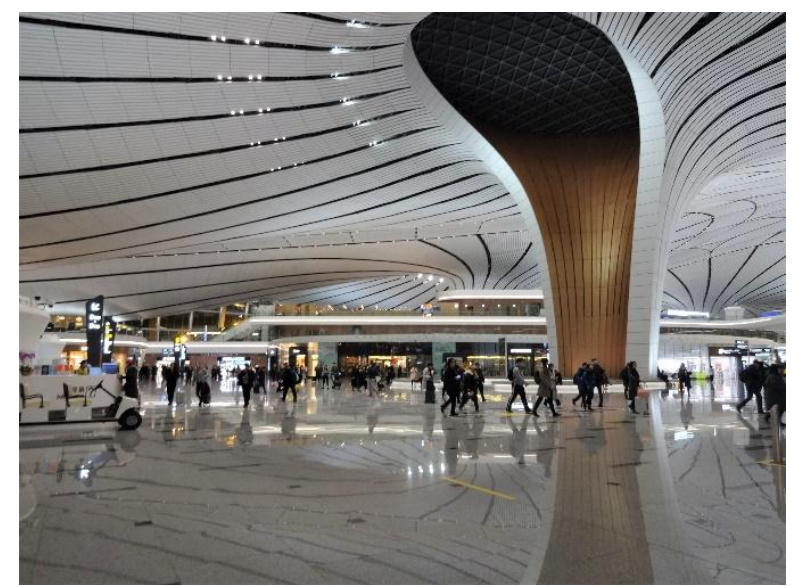

Photo1. Domestic restricted area 
International Journal of Engineering Research and Technology. ISSN 0974-3154 Vol.13, No.4 (2020), pp. 768-782

(C) International Research Publication House. https://dx.doi.org/10.37624/IJERT/13.4.2020.768-782

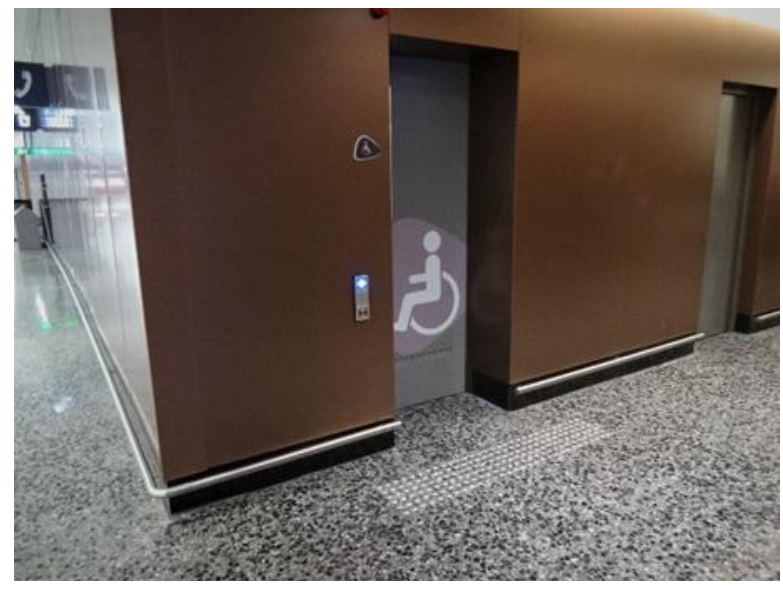

Photo2. The door of multipurpose

bathroom within the restricted area

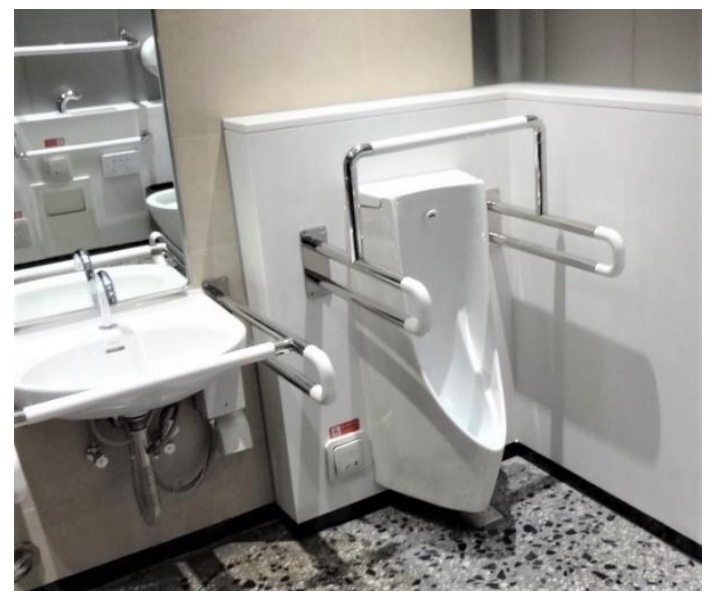

Photo3. Inside of multipurpose bathrooms within the restricted area

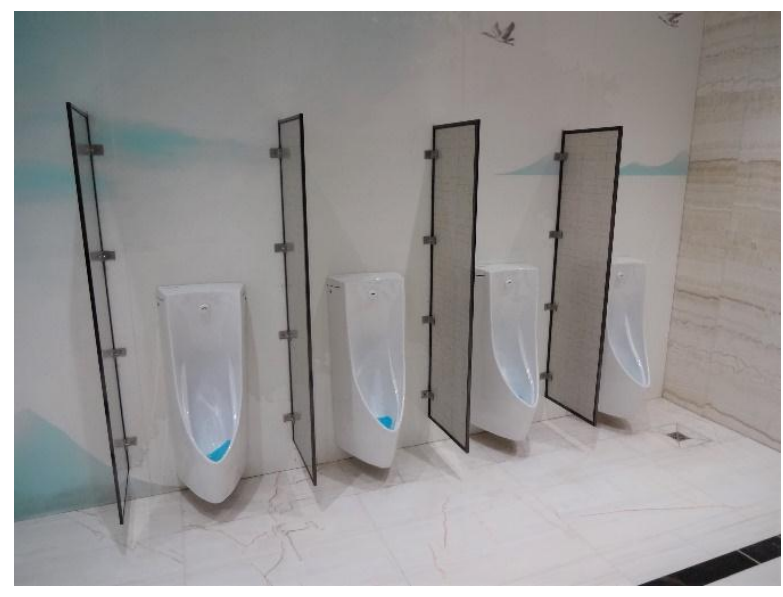

Photo4. The men's bathroom within the restricted area

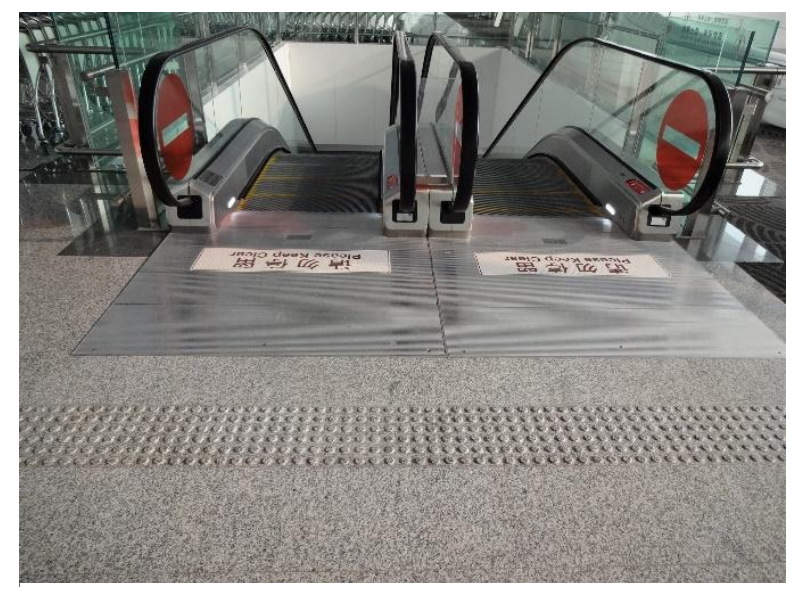

Photo5. Guidance blocks in front of escalators

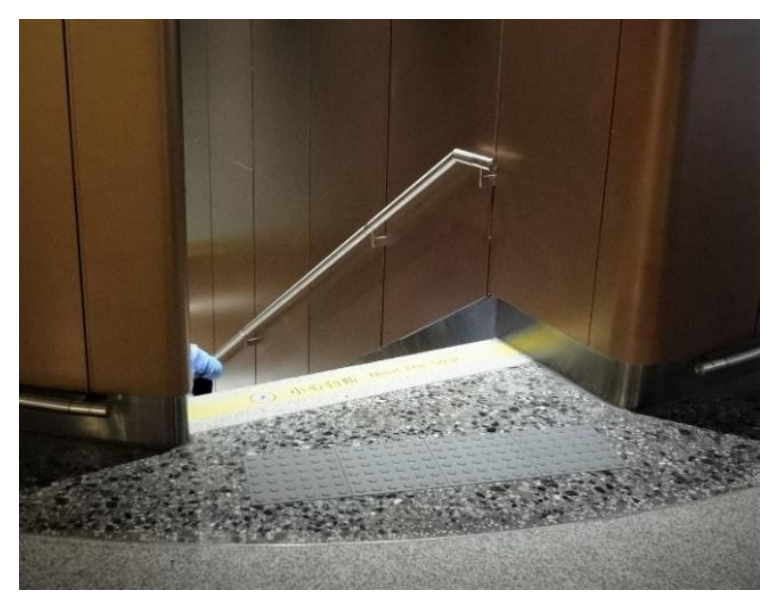

Photo6. blocks in front of staircases

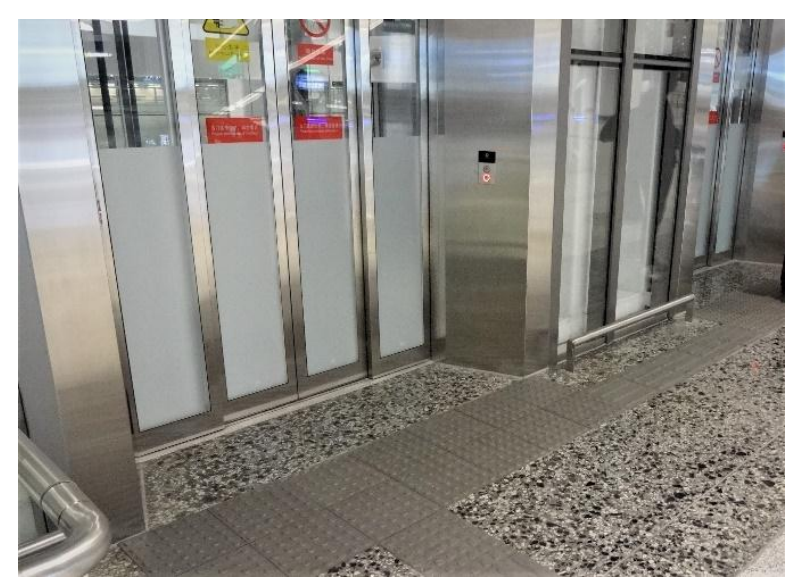

Photo7. Tactile walking surface indicators in front of elevators 


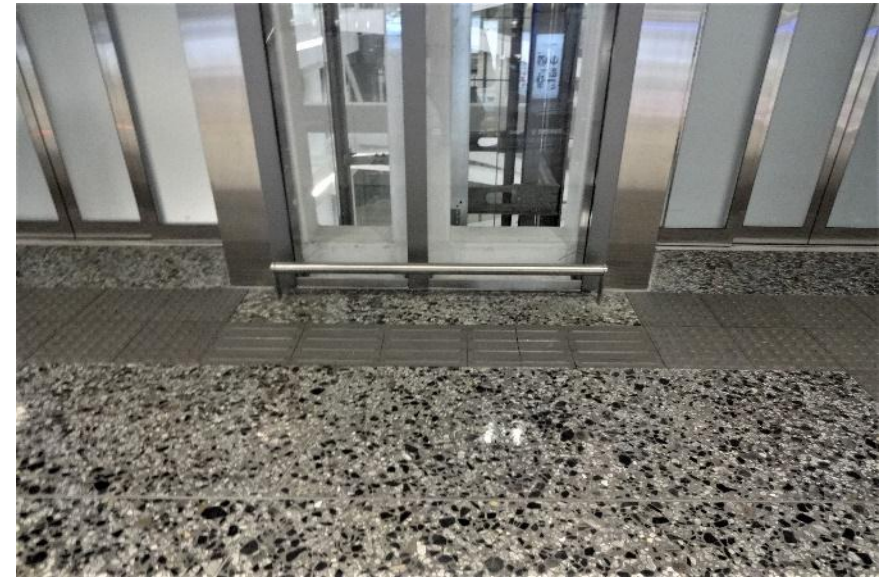

Photo8. Guidance blocks in front of elevators

There are guidance blocks installed on the third floor (Photo 9), where departure gates for domestic flights are located, while there are no such blocks installed almost anywhere on other floors. There is a mixture of guidance blocks of the same color with the floor surface and black vinyl chloride adherence-type guidance blocks. The black blocks have high visibility, but mixing different types of blocks may cause landscape issues.

On the ground floor with entrance/exit to taxi stands, there are black adherence-type guidance blocks leading to the information booth (Photo 10). There are door mats found placed on the blocks at entrance/exit of the airport (Photo 11). We have seen this kind of situations all over the world, but it is a shame to see the same situation at several locations in this brand new Beijing Airport.

There are unnecessary warning blocks found on the ground and the third floor (Photo 12). In places where the curve section for guidance blocks is less than 145 degrees [9], there should be warning blocks installed. However, if the angle is greater than 145 degrees, the visually impaired rarely notice the curve or even if they notice the curve they would rarely get confused. The installation of warning blocks in this case would rather

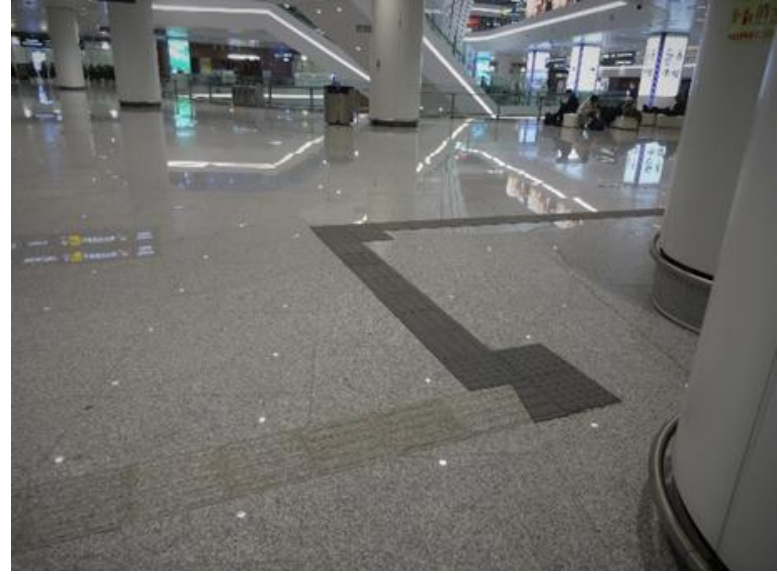

Photo9. Guidance blocks installed on the third floor

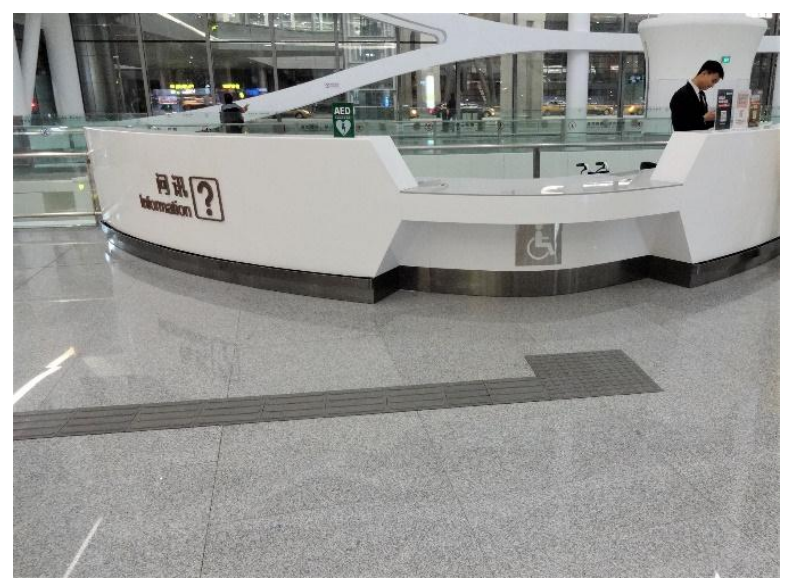

Photo10. Blocks leading to the information booth

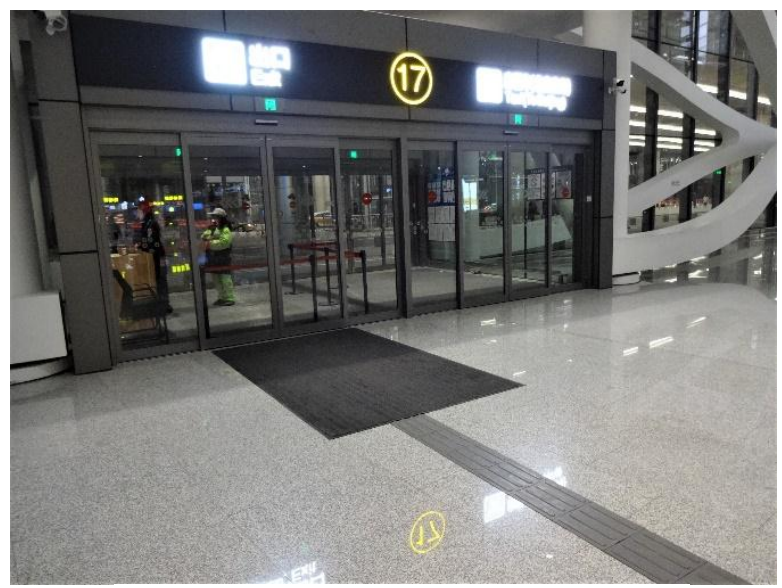

Photo11. Blocks at entrance/exit

lower the efficiency of their walking significantly because they would have to stop and search the direction.

$>$ There are three types of Tactile walking surface indicators in the airport; silver metal blocks, the 
blocks using the same material and color as the floor surface, and black adherence-type blocks. The black ones have high visibility, but they are only installed on the third and the ground floor. Any bold colors such as yellow are not used, thus it may be difficult for the people with weak eyesight to recognize them.

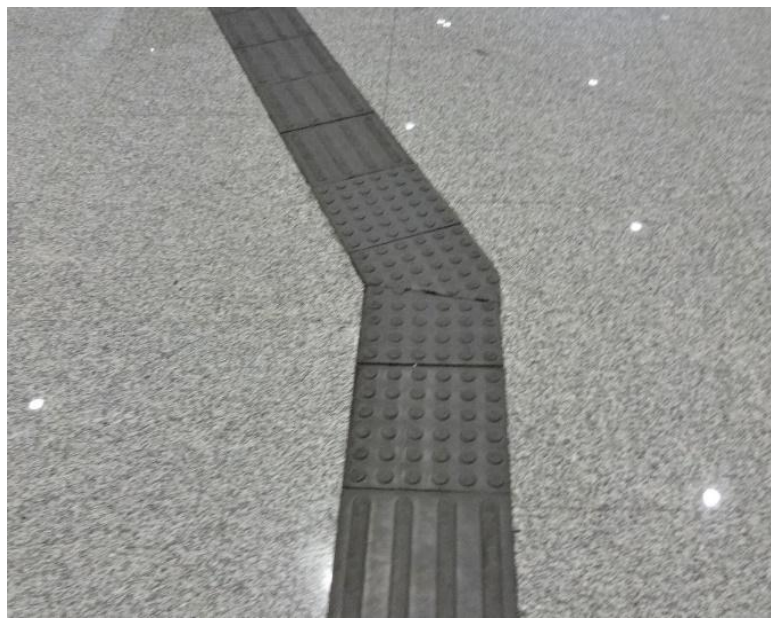

Photo12. Unnecessary warning blocks

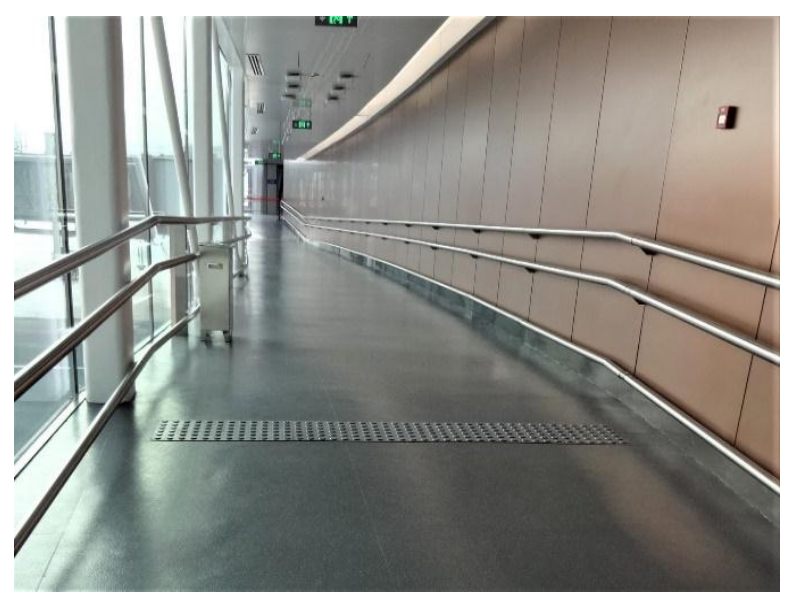

Photo13. Warning blocks installed at the beginning and the end of the slope from boarding gate to boarding bridge

b) Slopes in the airport

There are almost no slopes or stairs in the airport. The airport is designed for the passengers to use elevators or escalators when they are going up/going down. There is a gradual slope in the path from boarding gate to boarding bridge. At the beginning and the end of that slope there are warning blocks installed in a row (Photo 13). The visually impaired passengers would need human assistance at this particular location in the first place. These warning blocks are not only unnecessary but also interfering other pedestrians, thus they should be removed. c) Multipurpose bathrooms in the airport

$>$ In spite of the installation of warning blocks in front of multipurpose bathroom doors within the restricted area, which could be an obstacle, the bathroom interior is well equipped. The toilet seats are equipped with movable handrail and back support while makeshift beds (Photo 14), ostomate equipment, urinals equipped with handrail, as well as wash-basin for the people on wheelchair (Photo 15) are available. In addition, there are large emergency buttons placed at several locations where the people on wheelchair or those fallen on the floor may reach to ask for a help in case of emergency (Photo 16).

d) Elevators in the airport

$>$ There are a number of elevators in the airport, which are large and comfortably usable even with a wheelchair. Besides small car call buttons placed for individual elevator, there is an equipment to centrally control three elevator cars at once (Photo 17). Passengers may call an elevator by pressing a large button below the screen or pressing white round button located at the bottom of the support post of the equipment with their foot (Photo 18). The screen can be viewed clearly even from the visual line on wheelchair (Photo 19).

$>$ However, the equipment is independently installed in front of the elevator, which should be no doubt an "obstacle" for the visually impaired.

e) Information booth in the airport

$>$ There are desks with appropriate height for the people on wheelchair (Photo 20) provided at information booth on each floor. There are no Tactile walking surface indicators installed except for the information booth on the ground floor. Desks of appropriate height for the people on wheelchair are also provide at a money exchange counter (Photo 21).

f) Signposting in the airport

$>$ Informational guidance in the airport is mainly provided through screen display on a large equipment (Photo 22), but it is also available to get information by using telephone as well as call buttons for the disabled (Photo 23).

g) Ticket sales office in the subway station

$>$ The ticket machines are not usable for the people on wheelchair and the visually impaired (Photo 24). They need to ask a subway employee nearby to take them to a ticket sales office to buy tickets in person.

h) Access to platform in the subway station

$>$ The entrance gate to subway platform is an automated type. Tactile walking surface indicators are installed along the same booth that is used by wheelchair users (Photo 25), which is a fundamental mistake in a sense 
International Journal of Engineering Research and Technology. ISSN 0974-3154 Vol.13, No.4 (2020), pp. 768-782

(C) International Research Publication House. https://dx.doi.org/10.37624/IJERT/13.4.2020.768-782

that tactile walking surface indicators are being obstacle for the people on wheelchair.

$>$ There are guidance blocks installed leading to the platform. An elevator carries passengers going to the ticket gate (first basement level) from the subway platform (second basement level) (Photo 26). There are buttons for the people on wheelchair to use as well as Braille in the elevator (Photo 27). Those who take this elevator and get off on the first basement level arrive at a place indicated in the Photo28. There are no Tactile walking surface indicators here. We are only stunned to see such inconsistent barrier-free facility.

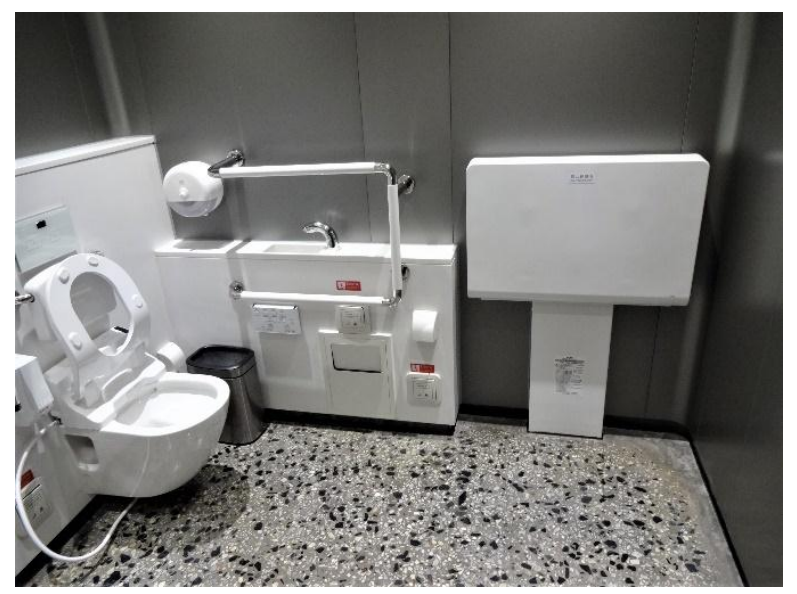

Photo14. Equipment of multipurpose bathroom 1

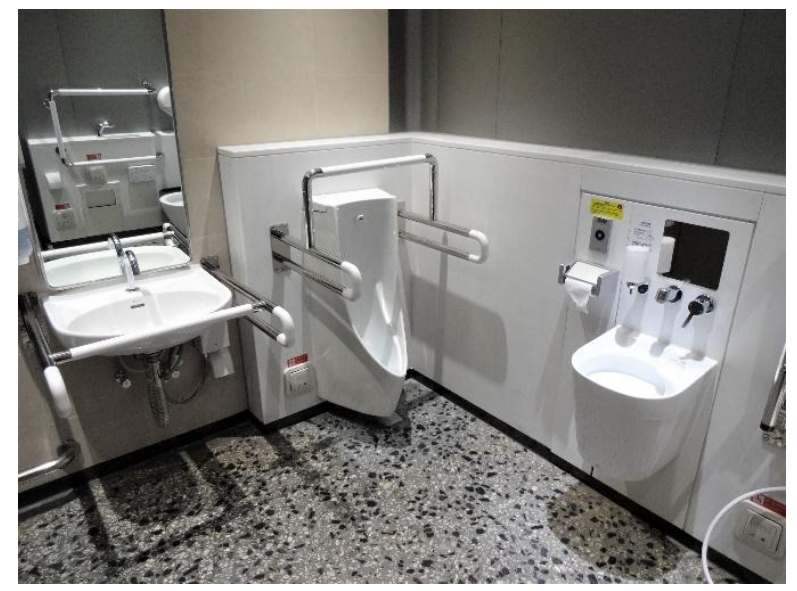

Photo15. Equipment of multipurpose bathroom 2

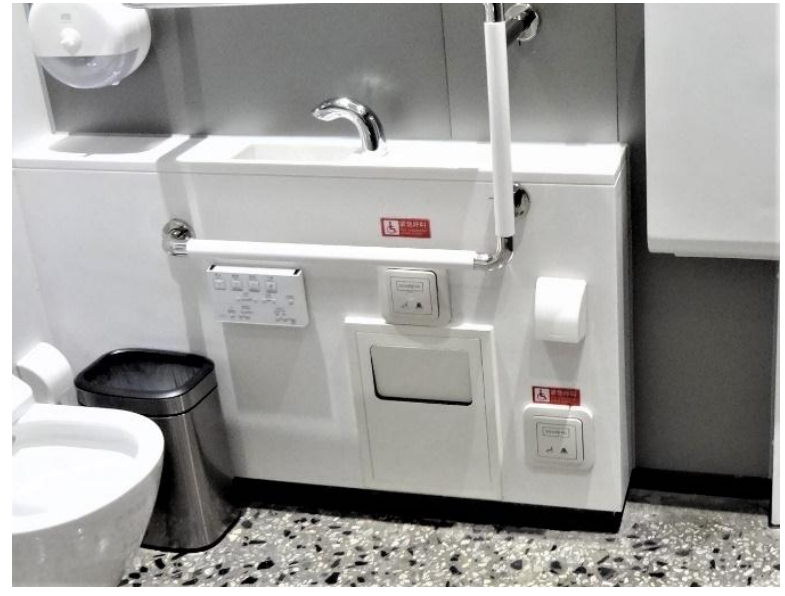

Photo16. Equipment of multipurpose bathroom 3

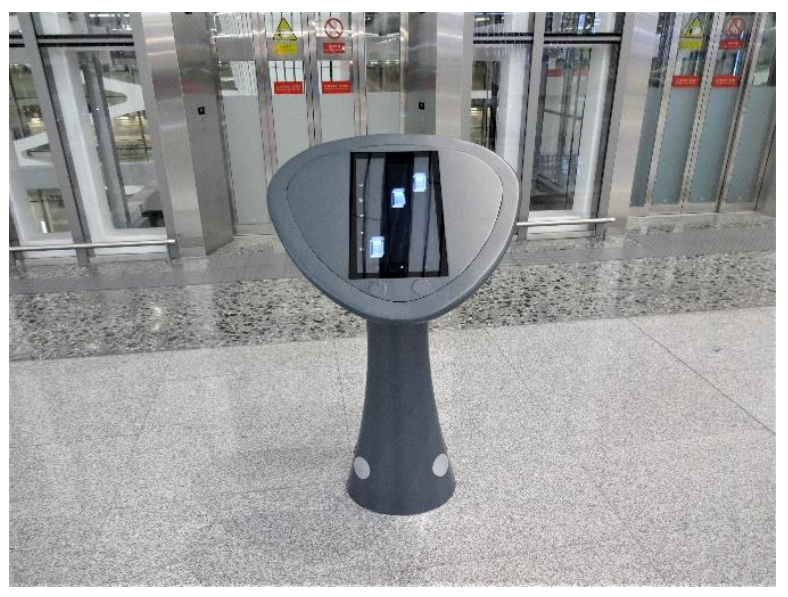

Photo17. Equipment to centrally control three elevator cars at once

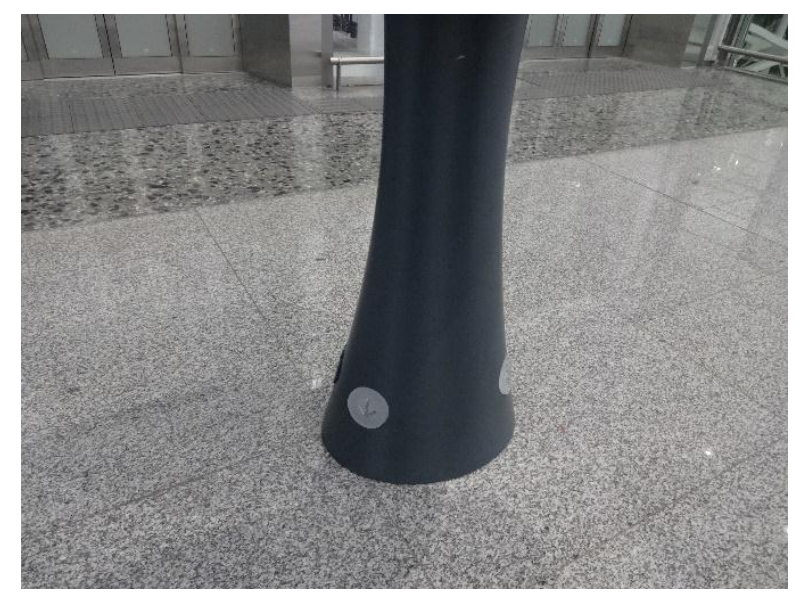

Photo18. Button located at the bottom of the support post of the equipment with their foot 
International Journal of Engineering Research and Technology. ISSN 0974-3154 Vol.13, No.4 (2020), pp. 768-782

(C) International Research Publication House. https://dx.doi.org/10.37624/IJERT/13.4.2020.768-782

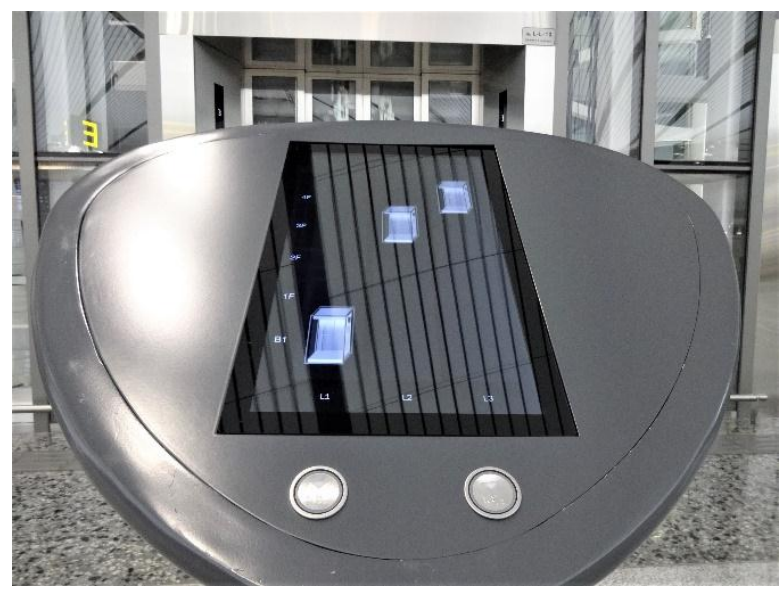

Photo19. The screen can be viewed clearly even from the visual line on wheelchair

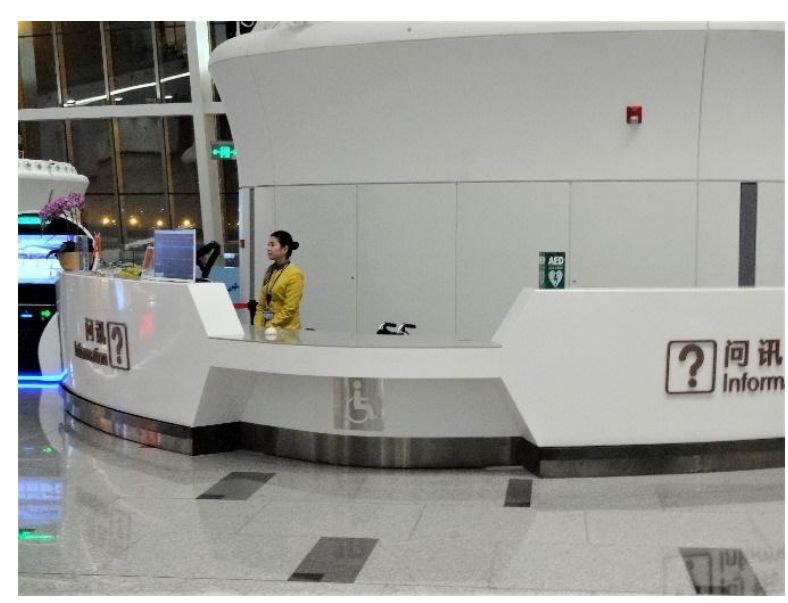

Photo20. Information booth

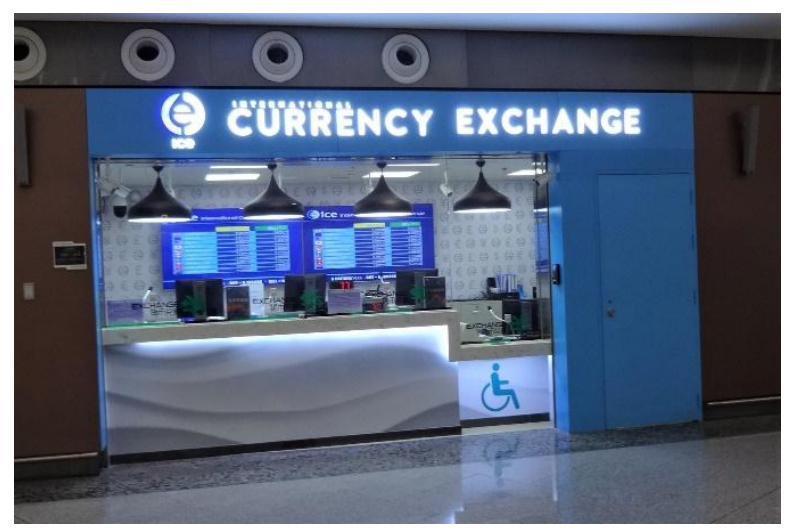

Photo21. Exchange counter

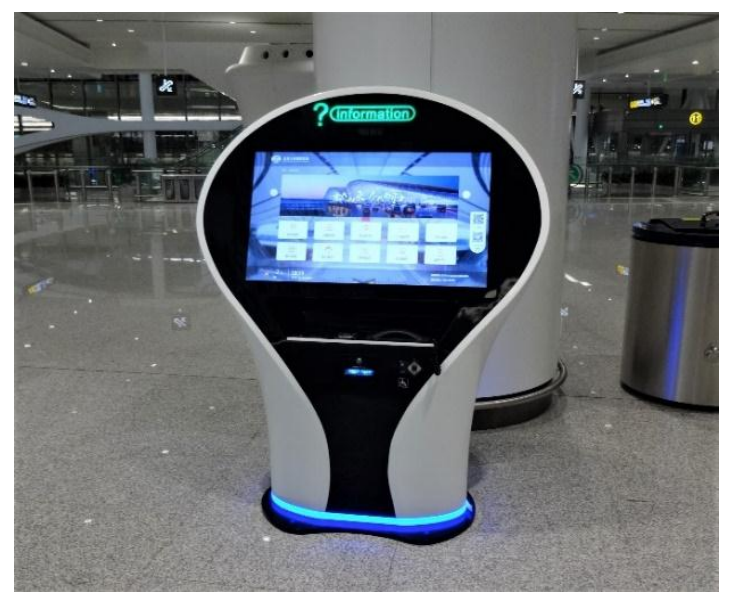

Photo22. Informational guidance provided through screen display on a large equipment

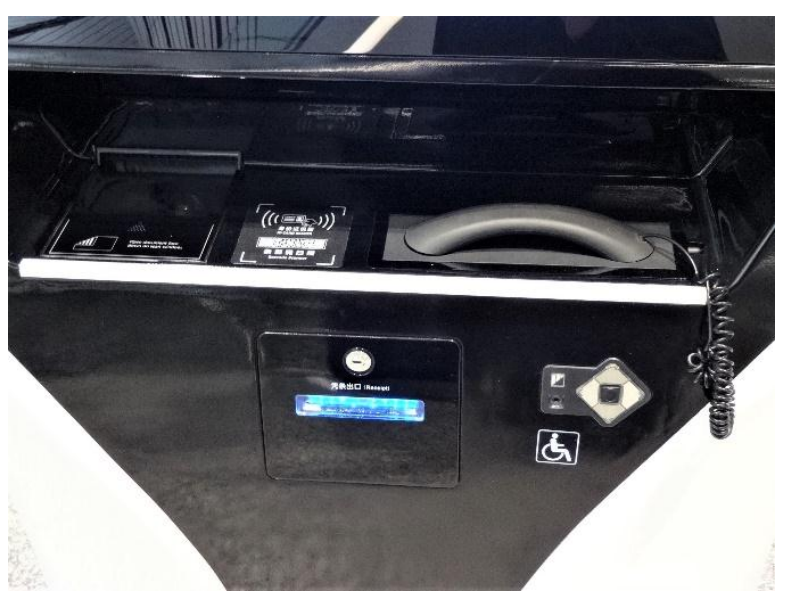

Photo23. Telephone and call buttons for the disabled

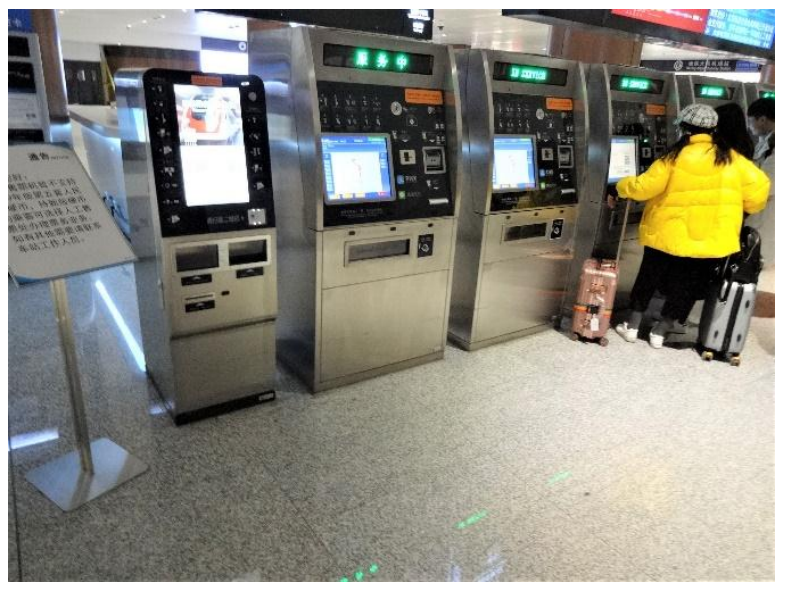

Photo24. Vending machine for subway tickets 


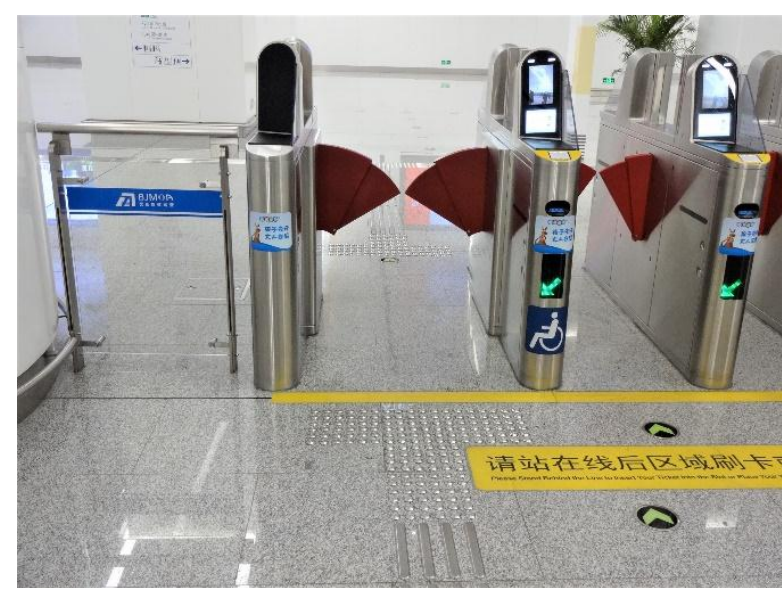

Photo25. Entrance Gate to the subway platform

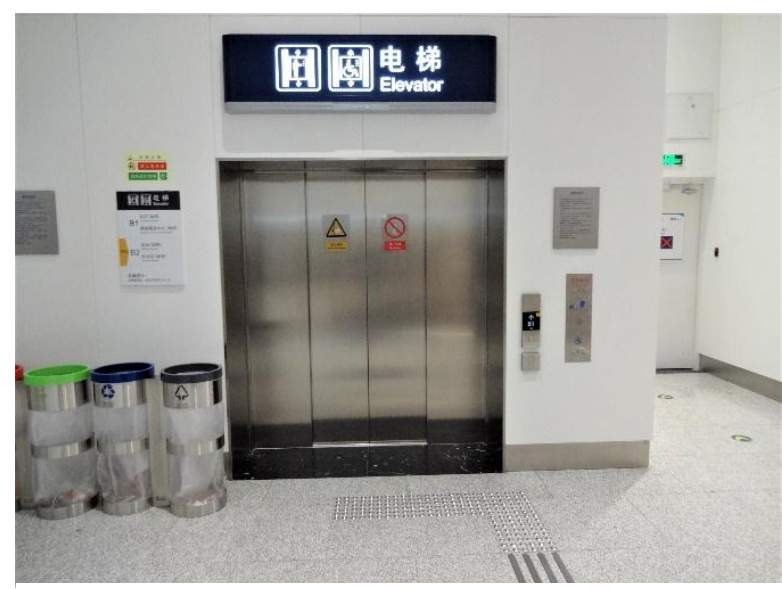

Photo26. Elevator of the subway station (second basement level)

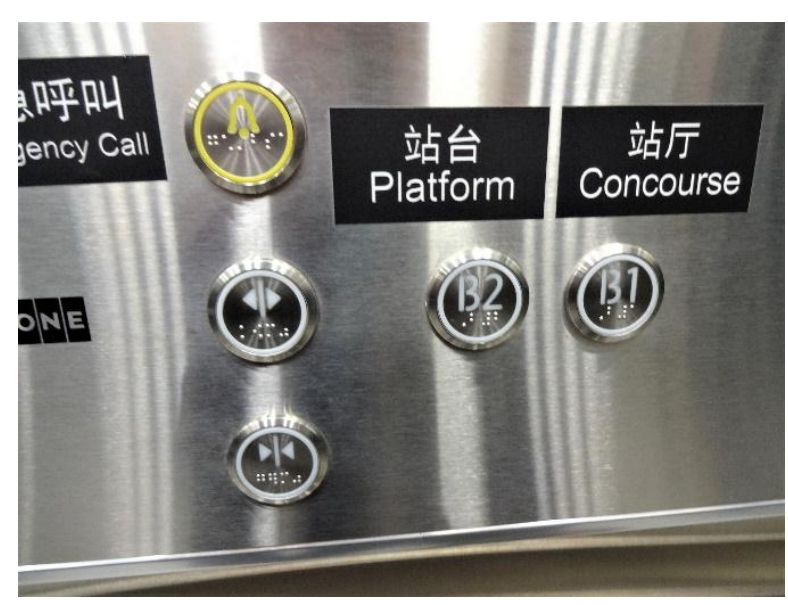

Photo27. Buttons in the elevator

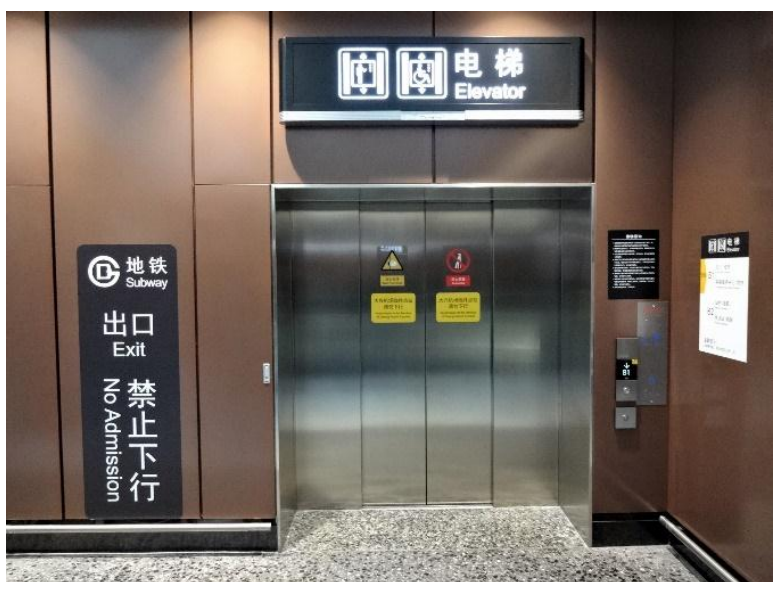

Photo28. Elevator of the subway station (first basement level)

i) Platform in the subway station

$>$ There are guidance blocks and warning blocks installed on the platform. The warning blocks are placed around the platform screen doors opening/closing area used by passengers getting on and getting off the subway (Photo 29). There are no Tactile walking surface indicators installed around the area of entering/exiting subway, so there are no obstacles for wheelchair users. In addition, the platform is quite large (Photo 30).

j) Multipurpose bathroom in the subway station

$>$ There is a multipurpose bathroom outside the ticket gate in the subway station (Photo 31). Although there are Tactile walking surface indicators installed, there is quite a distance from the bathroom door. The biggest problem of this bathroom is that the door can be opened only by moving down and pulling the door knob located at a high position. It is impossible for the people on wheelchair to use this bathroom independently.

$>$ The bathroom interior is equipped with minimum necessities except for toilet seats for small children, but there are other problems. Firstly, the emergency buttons are wrongly located and the number of the buttons installed is not sufficient. Secondly, there is a fixed handrail awkwardly located near the toilet paper holder making it difficult to reach the paper. Thirdly, the paper towels as well as hand dryers are placed too high, making it difficult for the people on wheelchair to use (Photo 32, 33).

k) Interior of the subway vehicles

$>$ Looking at the interior of the subway vehicle in Photo34, there is a large space near the door. But the depth of priority seats, that are provided two per 
vehicle, is the same as other seats (Photo 35).

1) Ticket sales office in the high-speed railway station

$>$ The ticket sales office in the high-speed railway station is not barrier-free (Photo 36). There is a security check point before entering the waiting area of the station. Passing that security check point, there is a manned service counter, where passengers can buy tickets (Photo 37). Foreigners and people with disabilities are supposed to buy tickets here at the counter.

m) Access to platform in the high-speed railway station

Passing the automatic ticket gate shown in Photo38, passengers go down to the platform on the second basement level by elevator or escalator. Although the waiting room in the high-speed railway station is large, there are no Tactile walking surface indicators nor guidance blocks leading to the ticket gate (Photo 39).

n) Platform in the high-speed railway station

$>$ There are platform screen doors installed on the platform of the high-speed railway station along with warning blocks which are $50 \mathrm{~cm}$ wide (Photo 40 ). The locations of the platform screen doors and the vehicle doors are not aligned that may cause significant confusion for visually impaired passengers (Photo 41). There are no Tactile walking surface indicators in the elevator transporting passengers from the platform level to the ticket gate level nor push buttons that the people on wheelchair may reach (Photo 42).

o) Multipurpose bathroom in the high-speed railway station

$>$ The entrance to the multipurpose bathroom in the high-speed railway station is too narrow for wheelchairs (Photo 43). There are no Tactile walking surface indicators installed, either.

$>$ There are minimum facilities provided inside the bathroom, but there are also problems. Firstly, there are no toilet seat back supports. Secondly, paper towels are placed too high. Thirdly, there are no ostomate facilities. And finally, the handrail on the left side of the toilet seat is too far from the seat (Photo 44, 45). There are urinals equipped with handrail. Urinals with handrail are provided in regular men's room as well (Photo 46), which is a difference from the men's room in the restricted area.

p) Interior of high-speed railway vehicle

$>$ The seats are all reserved. The vehicles have wide aisles (Photo 47).

q) Access to taxi stand

The taxi stand is located across the street from the ground floor exit of the airport building. There are Tactile walking surface indicators installed outside the building (Photo 48). There are car stops placed on the guidance blocks leading to a pedestrian crosswalk, which are dangerous barriers for the visually impaired (Photo 49).

$>$ There are Tactile walking surface indicators around the taxi stand and also in front of the taxi counter (Photo 50). The Tactile walking surface indicators in front of the taxi counter should be unnecessary because there is always somebody at the counter who is able to help the visually impaired to get a taxi. The Tactile walking surface indicators in this area are rather obstacles for wheelchair users to pass through. It is marked as "Barrier-free passageway" on the floor, but it is a wrong sign because the Tactile walking surface indicators become barrier for wheelchair users.

$>$ The areas below staircases and escalators are usually dangerous for the visually impaired with a risk of bumping their head against. Typically, there should be rails or pylons placed to avoid such accidents. There are very little countermeasures of the sort taken in this airport (Photo 51).

$>$ There is a small rail installed below staircases in the restricted area, but before the feet or canes of passengers get there, they would bump their head (Photo 52).

r) Transportation within the airport parking

$>$ There are two parking garages (three-storied) for short-term parking as well as underground parking for long-term parking. They are typical parking lot (Photo 53).

As there are no signs on the map in the parking lot, people would have no clue to find disabled parking space (Photo 54). There are some overhead signs along the vehicle route including a wheelchair mark (Photo 55).

s) Parking space for the disabled

$>$ There is disabled parking space for 18 vehicles in one of the parking garages. It is hard to find even coming closer because there are no wall signs or hanging signs at all except some small signs on the floor (Photo 56). Besides, there are pylons placed, so it is highly likely drivers with disabilities are unable to use the space.

t) Multipurpose bathroom in the airport parking

$>$ There is a multipurpose bathroom near the parking lot (Photo 57). The door can be opened with a push button, but the bathroom is small in width, and there are a lot of Tactile walking surface indicators installed in front of the door inhibiting entrance to the bathroom without taking a right-angled turn. The bathroom is absolutely full of barriers.

$>$ There are minimum facilities provided in the bathroom (Photo 58). But problems are that paper 
holders are placed too high which may not be reachable by wheelchair users and that there is only one emergency button. As a noteworthy merit to point out, the toilet seat is centrally placed so that users with paralysis on either side of the body may transfer their body to the toilet seat using the handrail.

u) Others

$>$ There are only two priority seats near the boarding gate in the waiting area, which is far too few (Photo 59).

\section{CONCLUSION}

$>$ A newly constructed airport in Beijing, Beijing Daxing International Airport, is highly evaluated as functionable facility with the innovative design and the use of state-of-the-art scientific technologies. However, when reviewing the premises and facilities from a barrier-free perspective, we found some problems, including the multipurpose bathroom in the subway station, which the people on wheelchair cannot use independently, and inconsistent arrangement of urinals equipped with handrail. Due to those reasons, we can hardly conclude it is a barrier free airport.

$>$ It is expected that those problems will be improved based on feedbacks from a number of users of the airport.

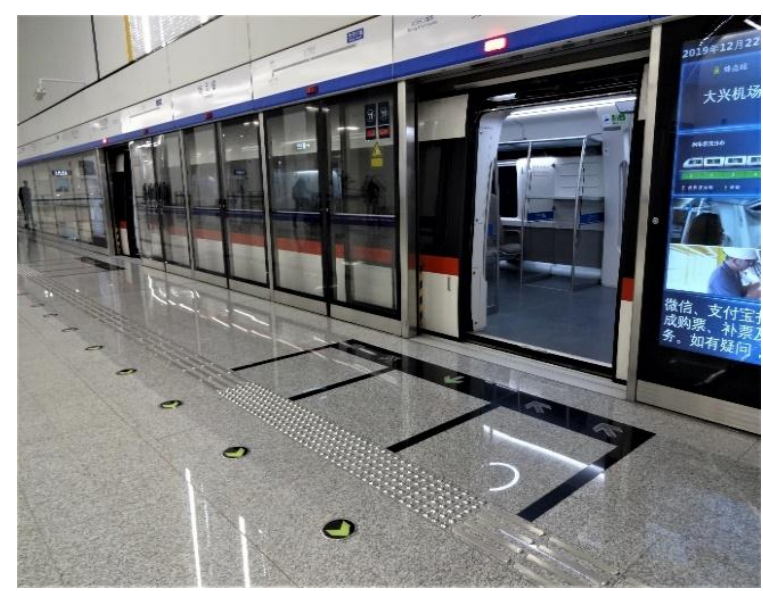

Photo29. Subway station platform 1

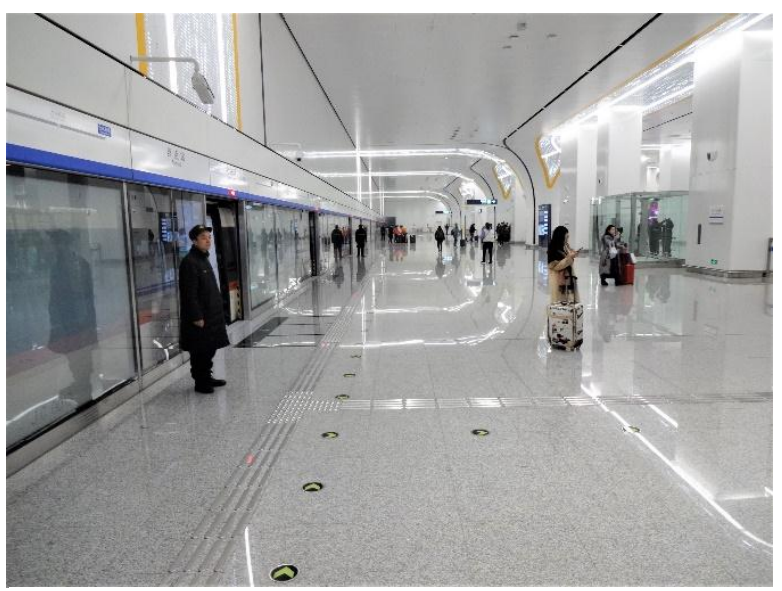

Photo30. Subway station platform 2

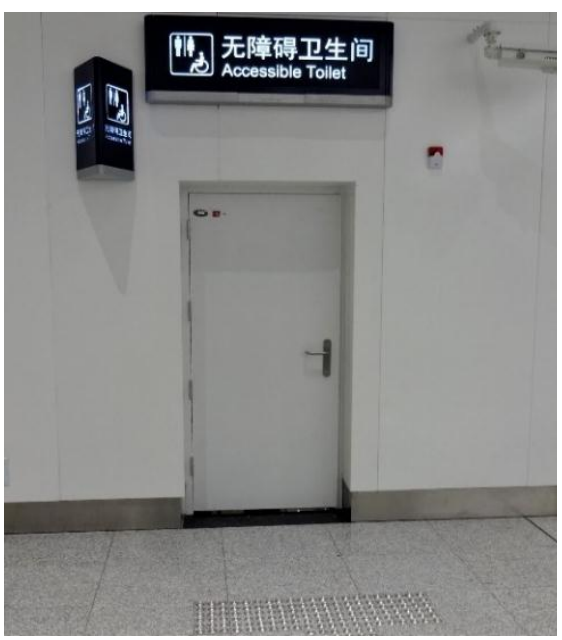

Photo31. Entrance of the multipurpose bathroom at subway station

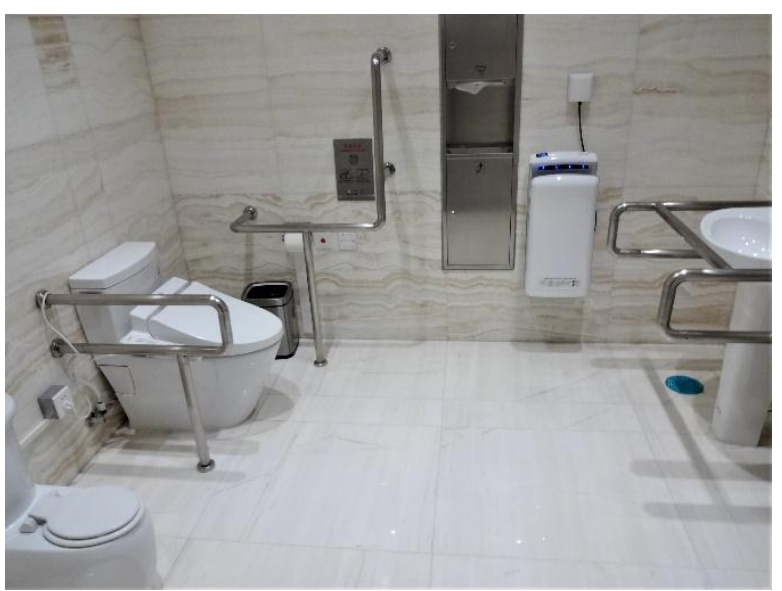

Photo32. Inside of the multipurpose

bathroom at subway station 1 


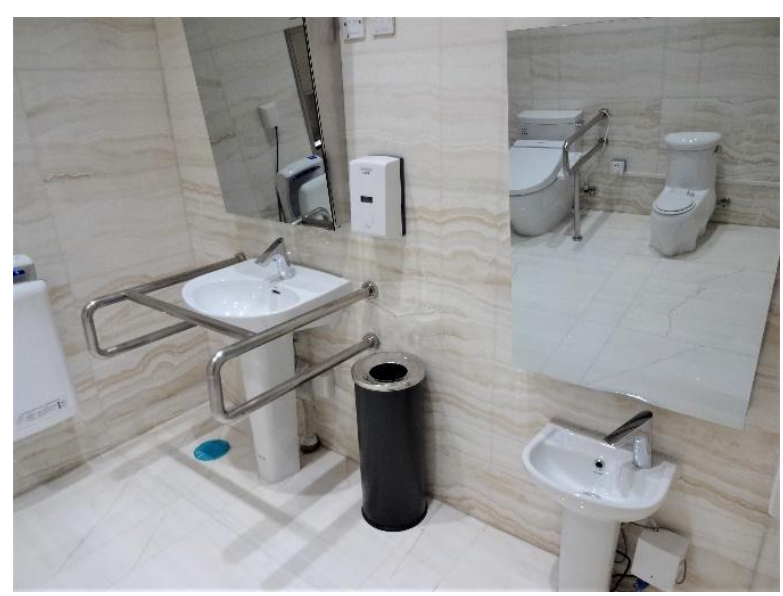

Photo33. Inside of the multipurpose

bathroom at subway station2

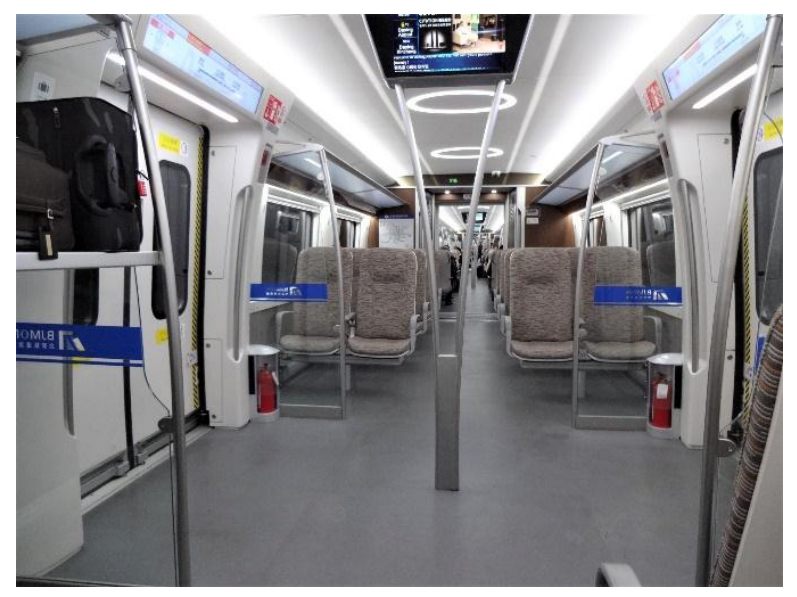

Photo34. Inside of subway vehicle

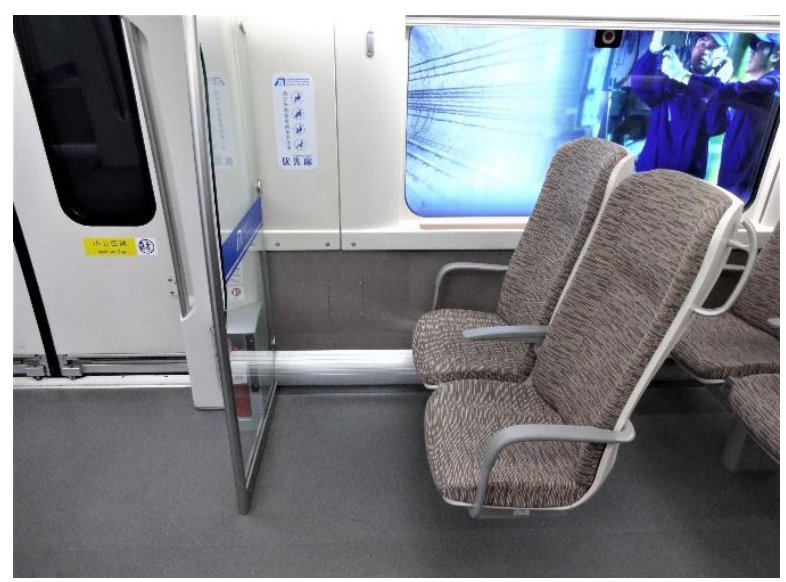

Photo35. Priority sheets of subway vehicle

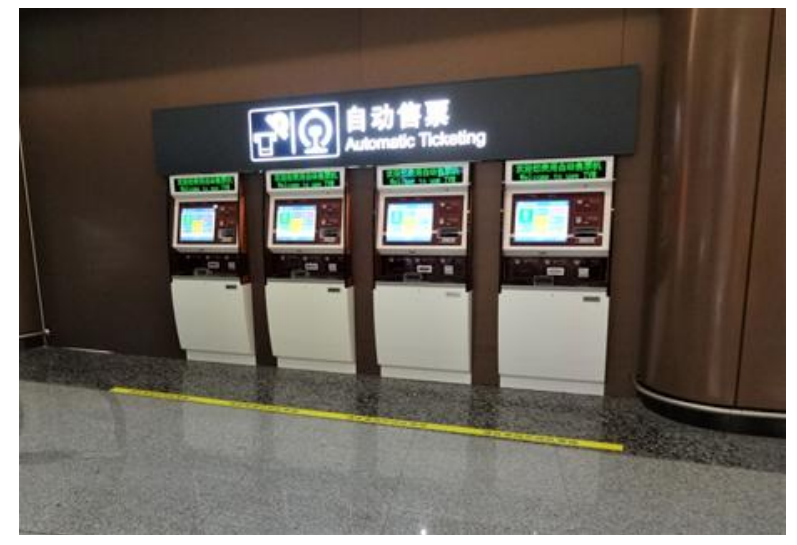

Photo36. Automatic ticketing for highspeed railway train

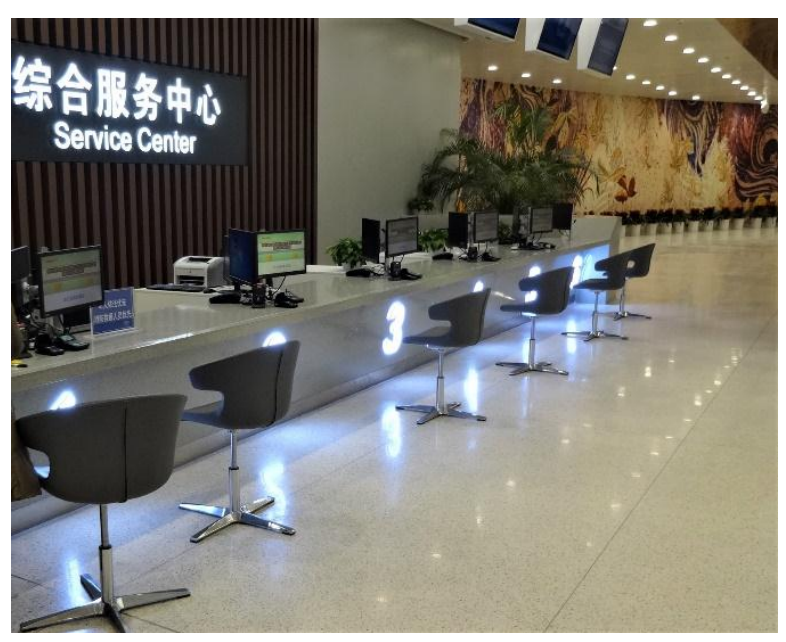

Photo37. Ticket sales office in the highspeed railway station

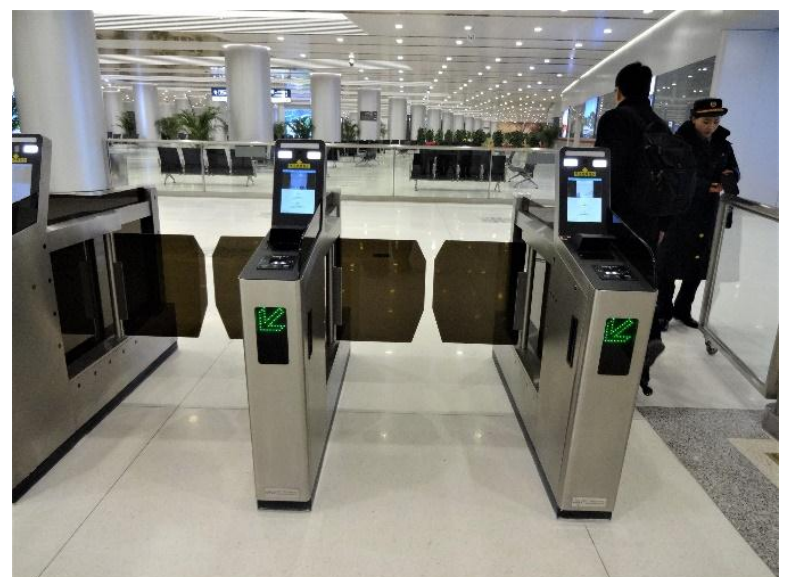

Photo38. Gate to platform in the highspeed railway station 


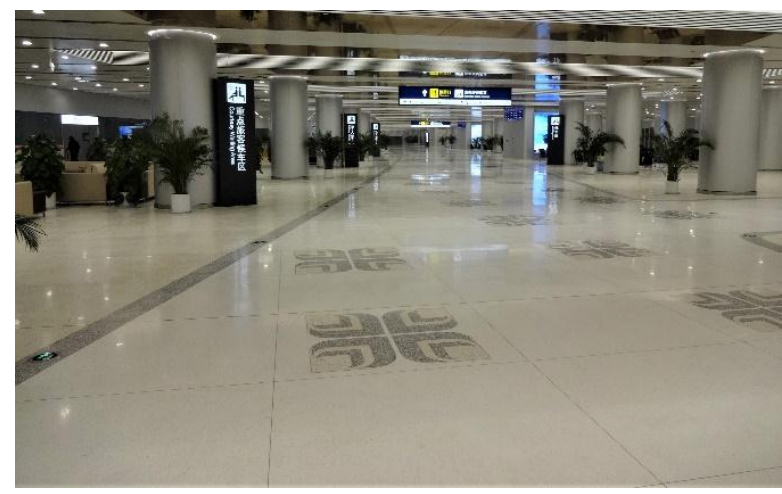

Photo39. Waiting room in the high-speed railway station

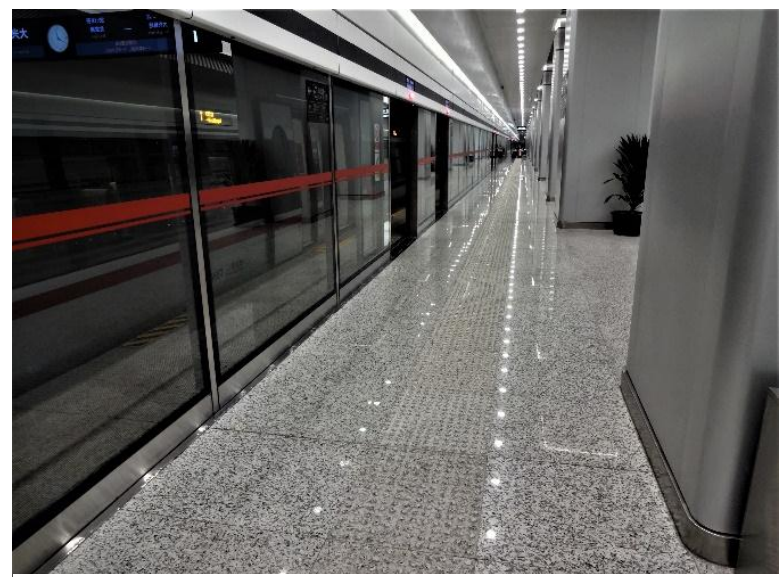

Photo40. Platform in the high-speed railway station 1

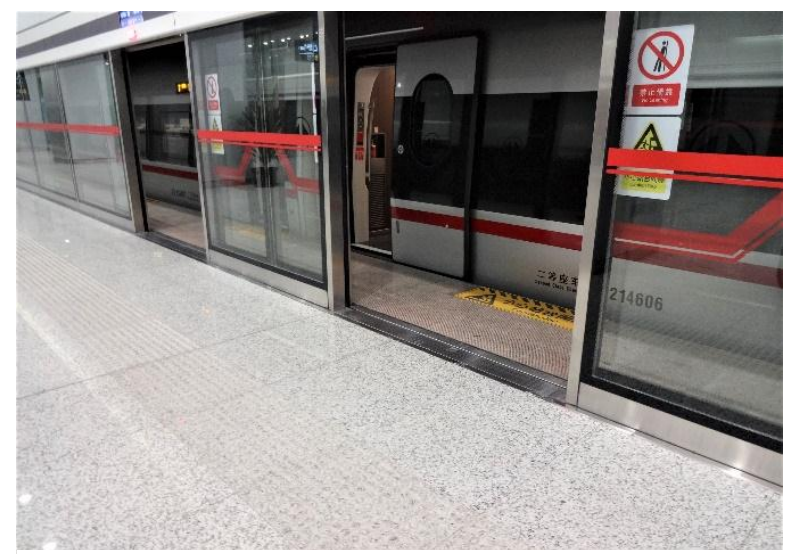

Photo41. Platform in the high-speed railwav station 2

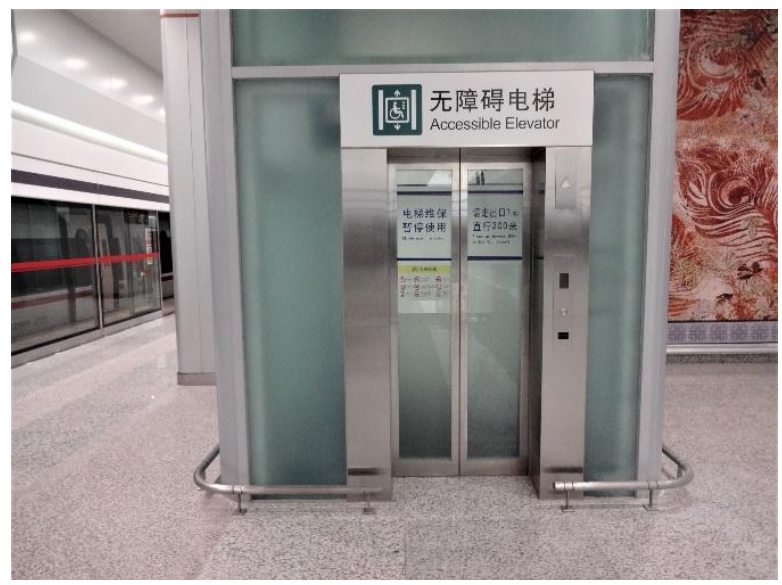

Photo42. elevator on the platform level

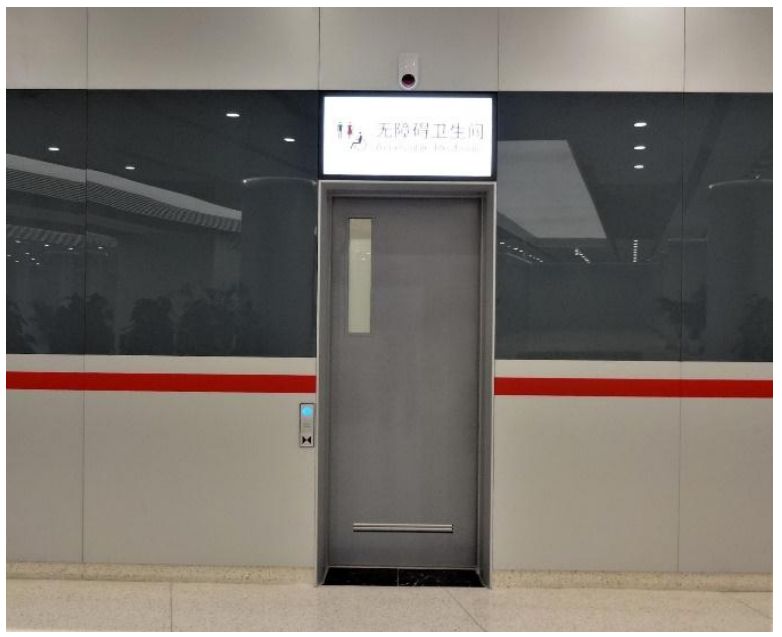

Photo43. Entrance to the multipurpose bathroom in the high-speed railway station

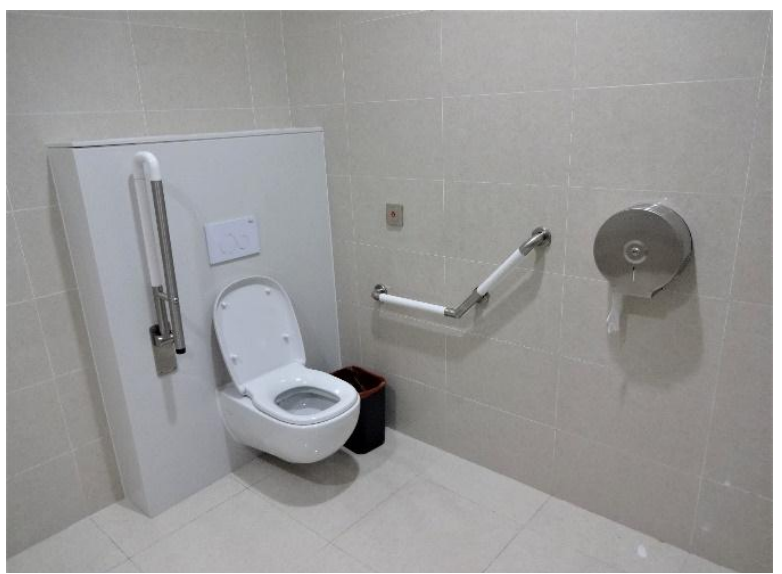

Photo44. Inside the bathroom of the highspeed railway station 1 
International Journal of Engineering Research and Technology. ISSN 0974-3154 Vol.13, No.4 (2020), pp. 768-782

(C) International Research Publication House. https://dx.doi.org/10.37624/IJERT/13.4.2020.768-782

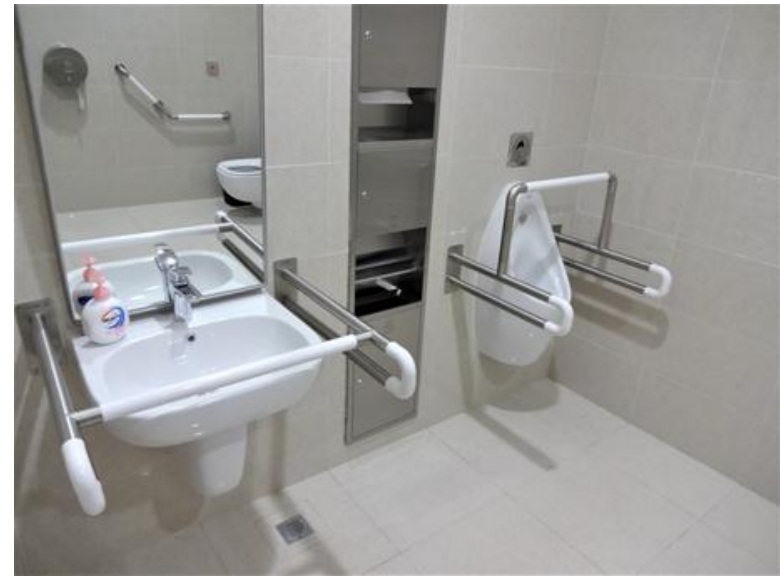

Photo45. Inside the bathroom of the highspeed railway station 2

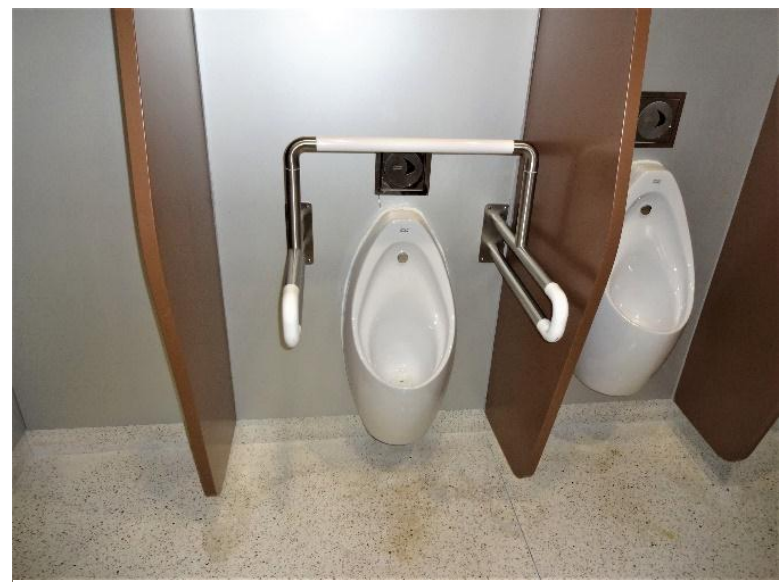

Photo46. Urinals for men toilet in the highspeed railway station

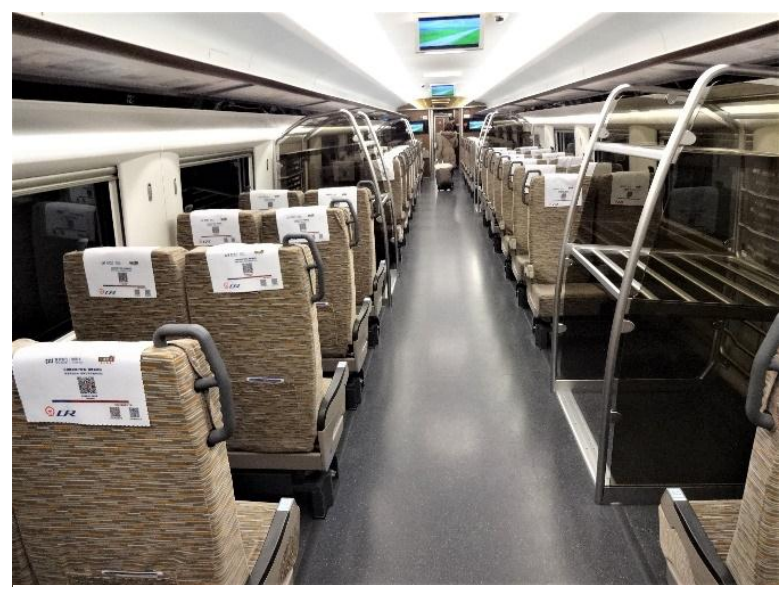

Photo47. Interior of high-speed railway vehicle

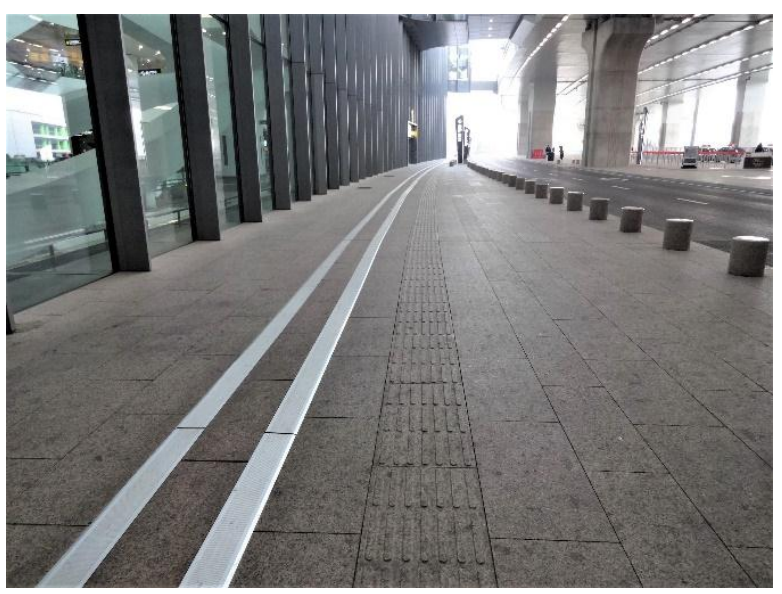

Photo48. Outside the building 1

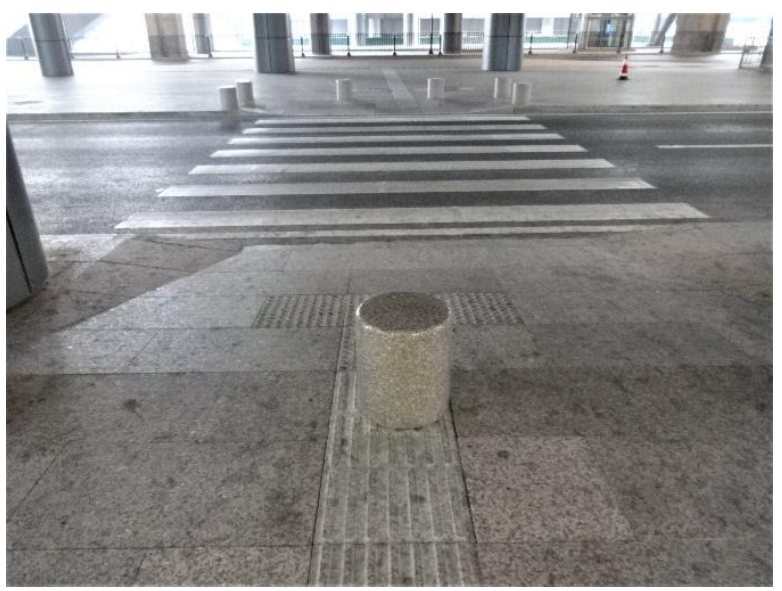

Photo49. Outside the building2

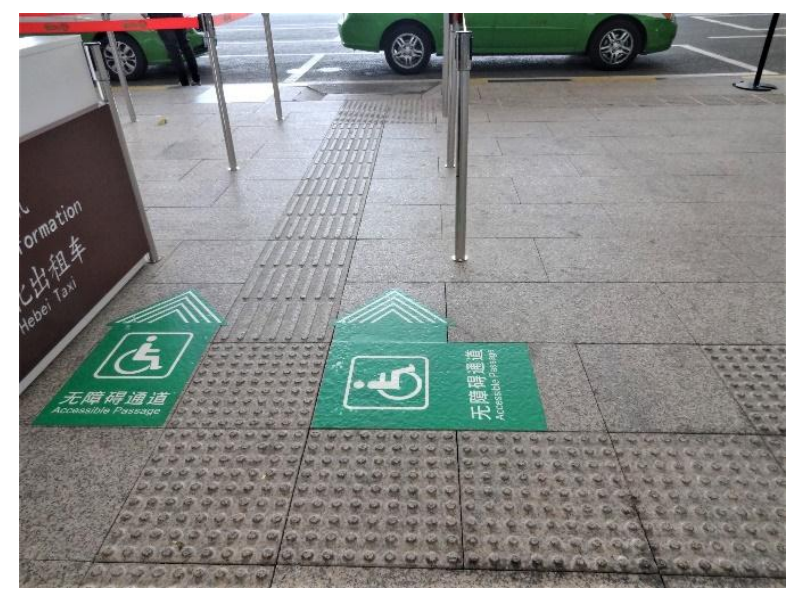

Photo50. Taxi stand 
International Journal of Engineering Research and Technology. ISSN 0974-3154 Vol.13, No.4 (2020), pp. 768-782

(C) International Research Publication House. https://dx.doi.org/10.37624/IJERT/13.4.2020.768-782

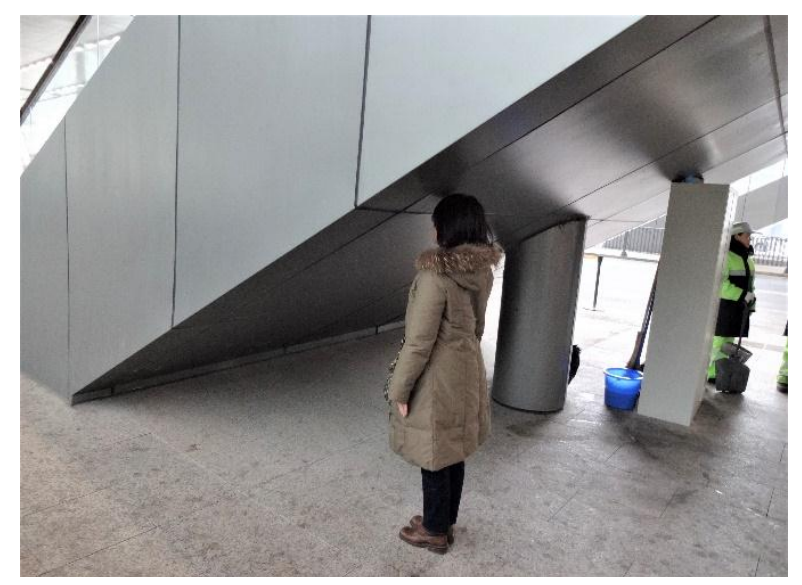

Photo51. Under the stairs outside the airport building

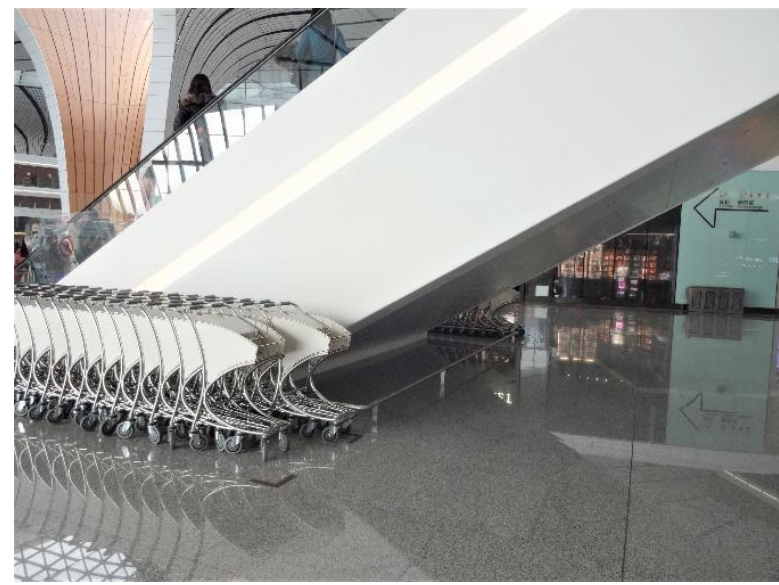

Photo52. Under the stairs in the restricted area

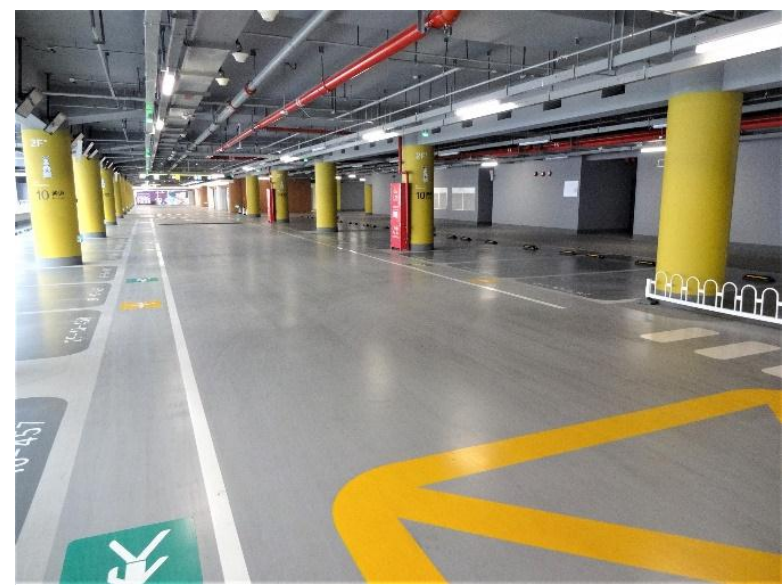

Photo53. Short-term parking lot

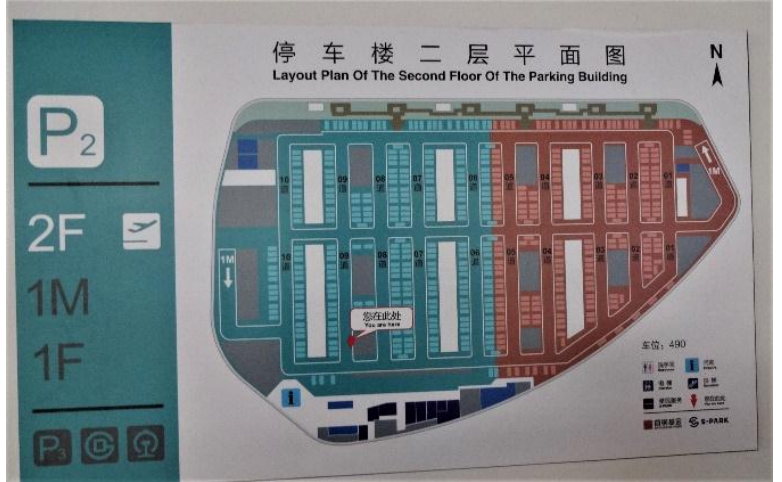

Photo54. Map of short-term parking lot

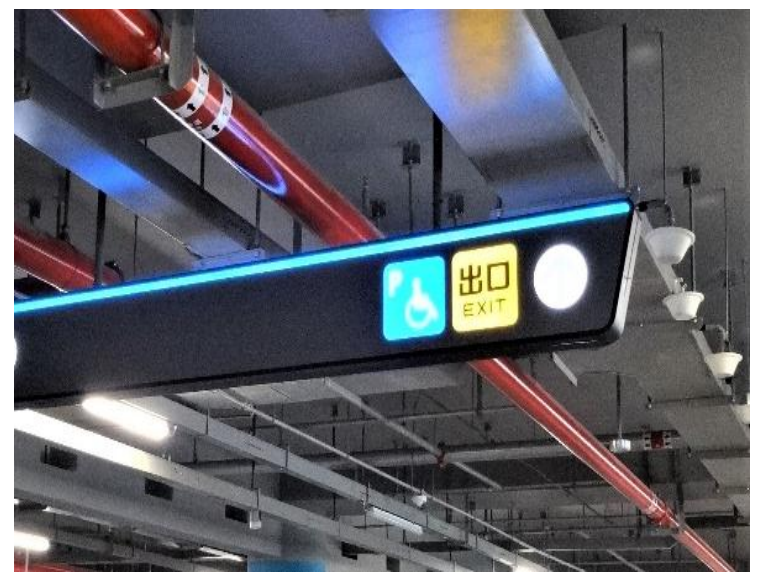

Photo55. Overhead signs along the vehicle route including a wheelchair mark

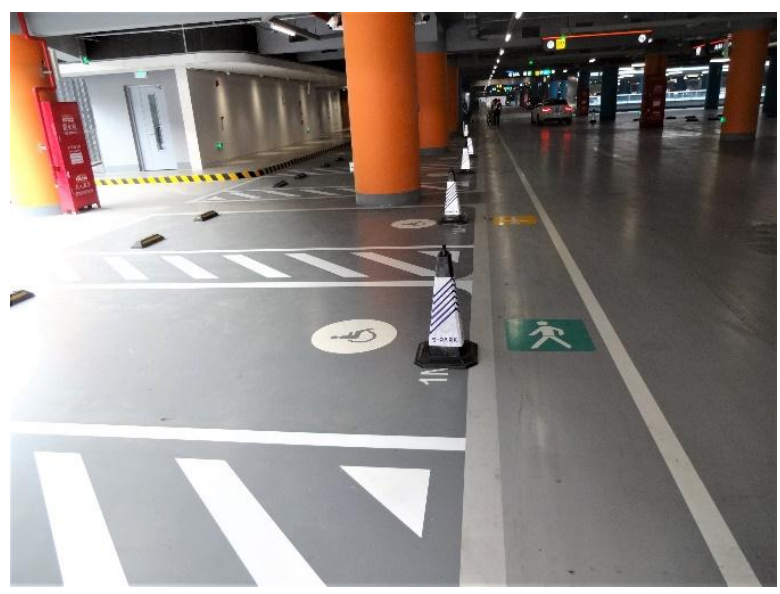

Photo56. Parking space for the disabled 


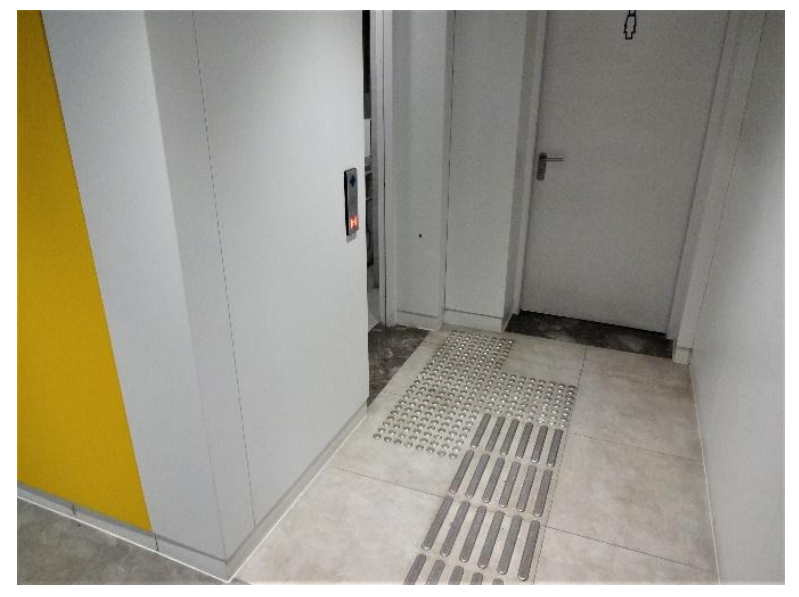

Photo57. Multipurpose bathroom in the parking lot

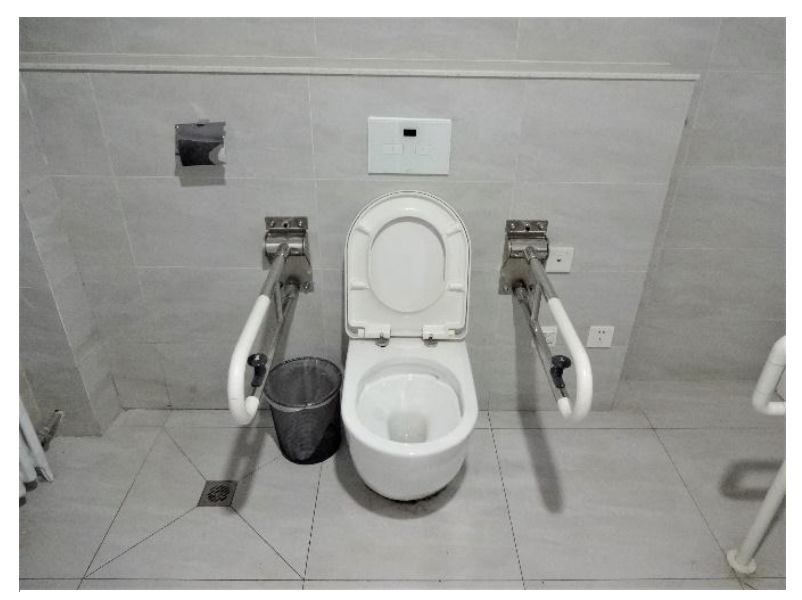

Photo58. Inside of the bathroom in the parking lot

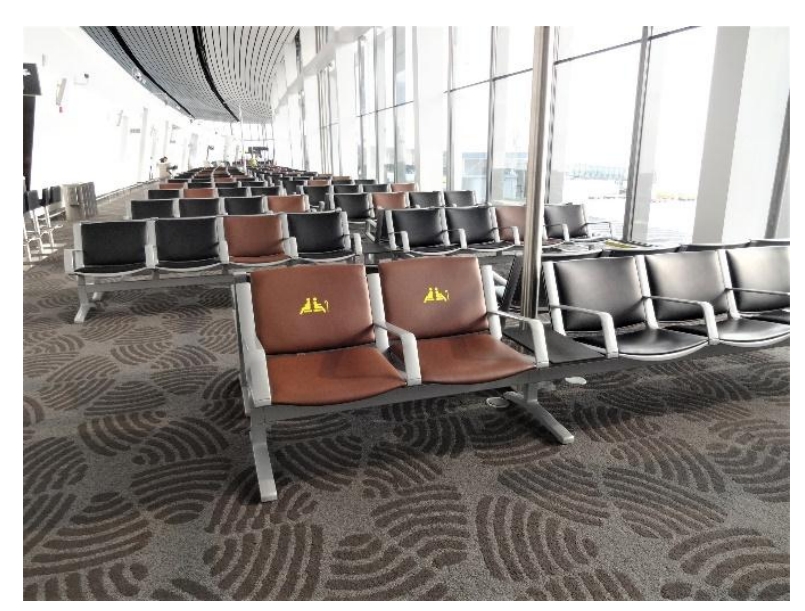

Photo59. Priority seats near the boarding gate in the waiting area

\section{REFERENCES}

[1] MIZUNO T. \& TOKUDA K. (2010) Barrier-free status of Shinkansen bullet trains and related facilities in South Korea, China and Taiwan: with a focus on the maintenance status of starting stations, terminal stations and bullet train cars, Journal of Understanding Special Needs, 11, 39-48, (in Japanese).

[2] TOKUDA K, \& MIZUNO T. (2018) Playing Environment of Indoor Playing Facilities in China: Comparison between Two Types of Facilities, Journal of Practical Human Service, 8, 27-34, (in Japanese).

[3] TOKUDA K., MIZUNO T. \& NISHIDATE A. (2018) The current Situation of Tactile walking surface indicators survey in Tibet Autonomous Region and Xinjian Uygur Autonomous Region, The $56^{\text {th }}$ annual convention of the Japanese Association of Special Education, P5-84, (in Japanese).

[4] TOKUDA K. \& MIZUNO T. (2018) Bicycle sharing that has become a new obstacle in urban areas in China due to abandoned bicycles on the street, The $77^{\text {th }}$ annual convention of Japanese Society of Public Health, P2203-4, (in Japanese).

[5] Mizuno T., Nishidate A., Ajimi A. \& Tokuda K. (2016) The Current Situation of Barrier Free Accessibility in Waterfront Areas, The Journal of Understanding Special Needs, 17, 29-44, (in Japanese).

[6] TOKUDA K. \& MIZUNO T. (2016) Characteristics of Ground Surface Indicators in Middle East and North Africa, The Asian Journal of Disable Sociology, 15, 2536.

[7] YAHATA M. (2014) Barriers While Moving with Infants as the Disadvantaged in Terms of Transportation with a Focus on Barriers for Buggy Users at the Children's Playground, Journal of Understanding Special Needs, 15, 39-47, (in Japanese).

[8] MIZUNO T. (2013) Installation Condition of Tactile Ground Surface Indicators and Problem in Central and Eastern Europe, The Asian Journal of Disable Sociology, 13, 49-63.

[9] TOKUDA K. \& MIZUNO T. (2011) Tactile Ground Surface Indicators, Fukumura Co., Tokyo, (in Japanese).

[10] MIZUNO T. \& TOKUDA K. (2019) Installation Situation of Tactile Walking Surface Indicators in Israel, International Journal of Engineering Research and Technology, 12 (5), 686-691. 